PII S0016-7037(96)00386-9

\title{
The complex stratigraphy of the highland crust in the Serenitatis region of the Moon inferred from mineral fragment chemistry
}

\author{
Graham Ryder ${ }^{1}$, MARC D. NORMAN ${ }^{2}$, and G. JeFFrey TAYlor ${ }^{3}$ \\ 'Lunar and Planetary Institute, Center for Advanced Space Studies, Houston, Texas 77058-1113, USA \\ ${ }^{2}$ GEMOC, School of Earth Sciences, Macquarie University, North Ryde, New South Wales 2109, Australia \\ 'Planetary Geosciences, Department of Geology and Geophysics, School of Ocean and Earth Science and Technology, \\ University of Hawai'i, Honolulu, Hawai'i 96822, USA
}

(Received May 6.1996; accepted in revised form November 7, 1996)

\begin{abstract}
Large impact basins are natural drill holes into the Moon, and their ejecta carries unique information about the rock types and stratigraphy of the lunar crust. We have conducted an electron microprobe study of mineral fragments in the poikilitic melt breccias collected from the Taurus Mountains at the Apollo 17 landing site. These breccias are virtually unanimously agreed to be impact melt produced in the Serenitatis impact event. They contain lithic fragments and much more abundant mineral fragments of crustal origin. We have made precise microprobe analyses of minor element abundances in fragments of olivine, pyroxene, and plagioclase to provide new information on the possible source rocks and the crustal stratigraphy in the Serenitatis region. These data were also intended to elucidate the nature of the cryptic geochemical component in breccias such as these with low-K Fra Mauro basalt compositions. We chose the finest-grained (i.e., most rapidly quenched) breccias for study, to avoid reacted and partly assimilated fragments as much as possible.

Most of the mineral fragments appear to have been derived from rocks that would fall into the pristine igneous Mg-suite as represented by lithic fragments in the Apollo collection, or reasonable extensions of it. Gabbroic rocks were more abundant in the target stratigraphy than is apparent from the Apollo sample collection. Some pyroxene and plagioclase, but probably not much olivine, could be derived from feldspathic granulites, which are metamorphosed polymict breccias. Some mineral fragments are from previously unknown rocks. These include highly magnesian olivines ( up to $\mathrm{Fo}_{94}$ ), possibly volcanic in origin, that exacerbate the difficulty in explaining highly magnesian rocks in the lunar crust. It appears that some part of the lunar interior has an $\mathrm{mg}^{*}[=100 \times \mathrm{Mg} /(\mathrm{Mg} / \mathrm{Fe})$ atomic $]$ greater than the conventional bulk Moon value of $80-84$. Other volcanic rocks, including mare basalts, and rapidlycooled impact melt rocks do not contribute significantly to the fragment population. Nor do ferroan anorthosites contribute more than a tiny part of even the plagioclase fragment population. A few mineral fragments that are consistent with the cryptic low-K Fra Mauro chemical component were found, and these appear to be from gabbroic sources. The mineral fragment populations cannot be mixed in their observed proportions to produce the whole rock composition, because the fragments are more refractory and deficient in $\mathrm{Ti}, \mathrm{P}$, and alkalis. A preferential contribution to the melt from a rock similar to sodic ferrogabbro can partly resolve the discrepancy.

The population of mineral fragments requires a very diverse population of igenous rocks that are not all related to each other, demonstrating the existence of a complex crust built of numerous separate igneous plutons. Many of these plutons may have crystallized at shallow depths. The chemical composition of the melt breccias, in combination with the mineral fragment data and an understanding of the cratering process, suggests that the deepest crust sampled by the Serenitatis impact (not necessarily the deepest crust) was basaltic in composition, including KREEP and gabbroic rocks like sodic ferrogabbro, and lacking abundant olivine-rich material. These were overlain by $\mathrm{Mg}$-suite rocks of varied types, including norites and troctolites that supplied most of the olivine mineral fragments. Granulites, which are metamorphosed and more feldspathic breccias, were abundant near the surface. Remote sensing indicates that the entire Serenitatis region lacks ferroan anorthosite, consistent with the results of our study. Copyright (C) 1997 Elsevier Science Ltd
\end{abstract}

\section{INTRODUCTION}

Lunar basins are natural drill holes into the crust. This allows us, at least in principle, to unravel the stratigraphy of the crust by detailed studies of impact melts produced during basin-forming events. The poikilitic melt breccias that form a chemical cluster and dominate the samples from the Taums Mountains collected on the Apollo 17 mission (AFGIT, 1973 ) are unique in that there is some certainty, and certainly virtual unanimity of opinion, as to their origin: the Serenitatis impact (Simonds, 1975; Winzer et al., 1977; Spudis and Ryder, 1981; Wilhelms 1987; and others). No one has of- fered any reasonable alternative origin. An origin as Imbrium impact melt samples (Rockow and Haskin, 1996) is inconsistent with the inferred age of Imbrium as probably no older than $3.836 \mathrm{Ga}$ (Dalrymple and Ryder, 1993) and the crystallization age of the Apollo 17 poikilitic melt breccias as $3.893 \pm 0.009(1 \sigma) \mathrm{Ga}$ (Dalrymple and Ryder, 1996a,b)

The geological context of the Apollo 17 poikilitic melt breccias is dependent on identification and interpretation of the ring structures of the Serenitatis basin (Fig. 1). Opinion on both has varied widely (Spudis, 1993), but there is reasonable agreement that the Taurus massifs at the landing site 


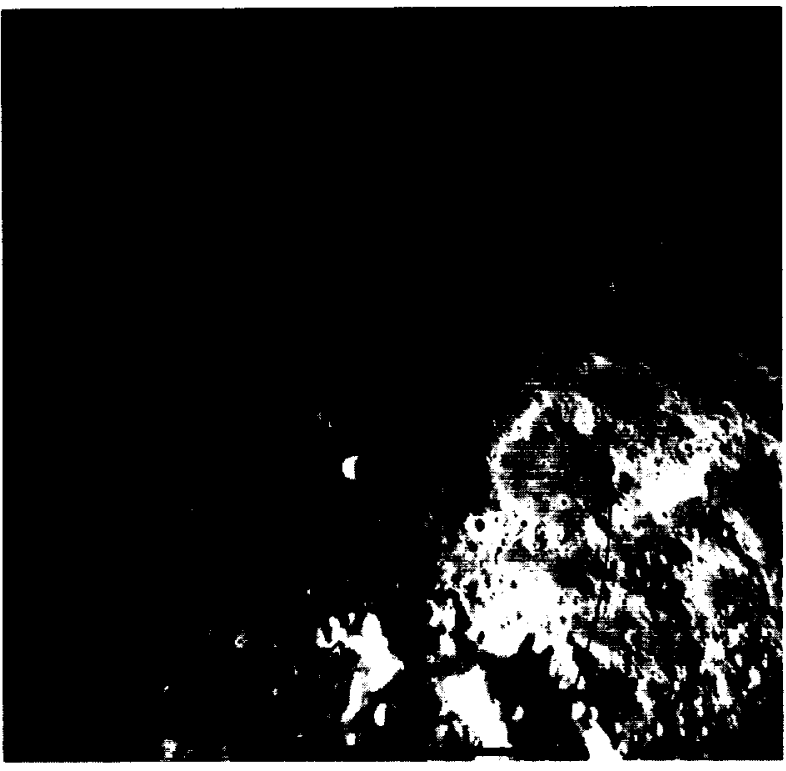

Fig. 1. Oblique view of the eastern rim of the Serenitatis basin from the south. Scale bar is about $50 \mathrm{~km}$ and applies to the southern proximal part. The image shows some postulated ring positions in the vicinity of the Apollo 17 landing site in the Taurus-Littrow valley (A). Solid lines from Reed and Wolfe (1975), Wolfe and Reed (1976) and Wolfe et al. (1981). Short-dash line from Wilhelms and McCauley (1971). Long-dash lines from Head (1979). Double line from Scott (1974). The Apollo 17 landing site falls outside the topographically prominent mare-highland boundary of the Serenitatis basin which is the lava-covered region in the west (left) part of the image. The main topographic rim in turn falls at or outside the transient cavity according to most interpretations. NASA Apollo photograph AS-17-M-0938.

lie just outside the main basin topographic rim and thus outside the transient cavity of Serenitatis (e.g., Head, 1979). If so, the samples are not part of a coherent melt sheet that lined the basin but instead melt that exited the transient cavity, presumably by outward flow or spilling (Fig. 2). Such an origin is consistent with their petrography: They are fine-grained and fragment-bearing and occur in texturally heterogeneous units within boulders (Simonds, 1975). For the rest of this paper, these poikilitic samples will be referred to as Apollo 17 Serenitatis melt breccias.

The Apolto 17 Serenitatis melt breccia samples have a range of petrographic textures and grain sizes (even coexisting within single boulders), but all contain lithic and mineral fragments (Figs. 3, 4); none is a coarse-grained fragmentfree melt (Simonds, 1975; Spudis and Ryder, 1981). The few large lithic fragments include dunite, troctolite, norite, and other types of igneous rock, as well as feldspathic granulites. Lithic fragments of ferroan anorthosite are conspicuously absent, and even absent from all but sub-centimeter rock fragments at the Apollo 17 landing site (Warren et al., 1991; Warren, 1993; Jolliff et al., 1996). Mare basalts and other volcanic rock types as well as older impact melt breccias and other near-surface rocks, such as regolith breccias, appear to be rare if not absent as lithic fragments in the Serenitatis melt breccias.

Mineral fragments in the Apollo 17 Serenitatis melt breccias far outnumber the lithic fragments. Conceivably, the mineral and lithic fragments each preferentially represent different parts of the excavated zones. Several studies have shown the ranges of major element compositions of silicate mineral fragments within and among these melt breccias (e.g., Simonds, 1975; Chao et al., 1975; Dymek et al., 1976). Little attention has been paid to the minor element abundances in the silicate mineral fragments that may be more sensitive to the chemical and physical environment in which their protoliths originally formed. Varied volcanic and plutonic environments, and subsequent subsolidus cooling and metamorphism, produce varied minor element abundances in particular minerals that can be used to better characterize and identify the source rocks of silicate mineral fragments in breccias than can major element characteristics of the minerals alone.

In this study, we have acquired abundant major and minor element chemical compositions of olivine, pyroxene, and plagioclase fragments in melt breccias formed in the Serenitatis impact event to characterize the crustal rocks in the vicinity of the target area (Ryder,1984a; Norman et al., 1992). We use these compositions to characterize the rock types in their sources. We have previously tested the method on samples of terrestrial impact melt from the Mistastin Lake structure in Canada (McCormick et al., 1989). The Mistastin Lake structure is about $28 \mathrm{~km}$ in diameter, has a homogeneous melt sheet exposed at several places around the crater rim, and has a fairly simple target stratigraphy (Grieve, 1975). We have also applied the method to black and white melt breccia samples 15445 and 15455 collected on the Apollo 15 mission (Spudis et al., 1991) that are strong candidates for Imbrium melt breccias (Ryder and Bower, 1977). By integrating our Apollo 17 mineral fragment data with other information about the crust, both regionally and globally, and by comparing the results with those for known rock types and the Apollo 15 melt breccias, we expect to shed light on crustal stratigraphy and origin of the lithologic components in the Serenitatis region.

\section{MINOR ELEMENT ABUNDANCES AND ROCK TYPES}

The major element compositions of silicate minerals on the Moon are determined first by crystallization from indigenous igneous (volcanic or plutonic) melts or impact melts, and secondly by any subsolidus equilibration or subsequent metamorphism. The major element compositions are commonly not distinctive and certainly not diagnostic of particular parent rocks, particularly those minerals that are dominantly binary, such as olivine and plagioclase. For more complex minerals, such as pyroxene, the major element compositions can be more informative as to cooling rates and thus crystallization environment of the igneous rock, or subsequent metamorphism, because of the variety of crystal structures, possible ionic substitutions, and exsolutions (e.g., Boyd and Brown, 1969; Papike et al., 1991; McCallum and O'Brien, 1995). While the presence and nature of majorelement variation (i.e., zoning) of silicate minerals can be informative, many mineral fragments in breccias are too small for its recognition and characterization.

Minor element abundances in the silicate minerals provide more diagnostic information of the physical or chemical envi- 
ronments, or both, of the igneous parent. For instance, volcanic olivines have higher $\mathrm{CaO}$ contents than do plutonic olivines (Simkin and Smith, 1970), and lunar volcanic plagioclases have higher $\mathrm{FeO}$ abundances than do plutonic plagioclases (Longhi et al., 1976). Thus, the meteorite Nakhla can be confidently identified as a volcanic rock on the basis of the high $\mathrm{CaO}$ content in its olivines alone, consistent with the zoning patterns and compositions of the other minerals and the petrography of the rock. Although the detailed mechanisms and un derlying causes behind particular element abundances might be complicated and even unknown (for instance, whether the low $\mathrm{FeO}$ abundance of lunar plutonic plagioclase is a primary or metamorphic effect), abundances of the minor elements in the silicate minerals at least allow an empirical discrimination among possible source rocks. Among terrestrial rocks, for instance, olivines from komatiites can be distinguished from all other olivines on the basis of their high $\mathrm{Cr}_{2} \mathrm{O}_{3}$ abundances (Renner et al,, 1994). Investigation of minor elements in silicate minerals in lunar rocks has elucidated their origins (e.g., Bence and Papike, 1972; Smith, 1974; Steele and Smith, 1975; Longhi et al., 1976). The same sorts of inference can be made for discrete mineral fragments in melt breccias.

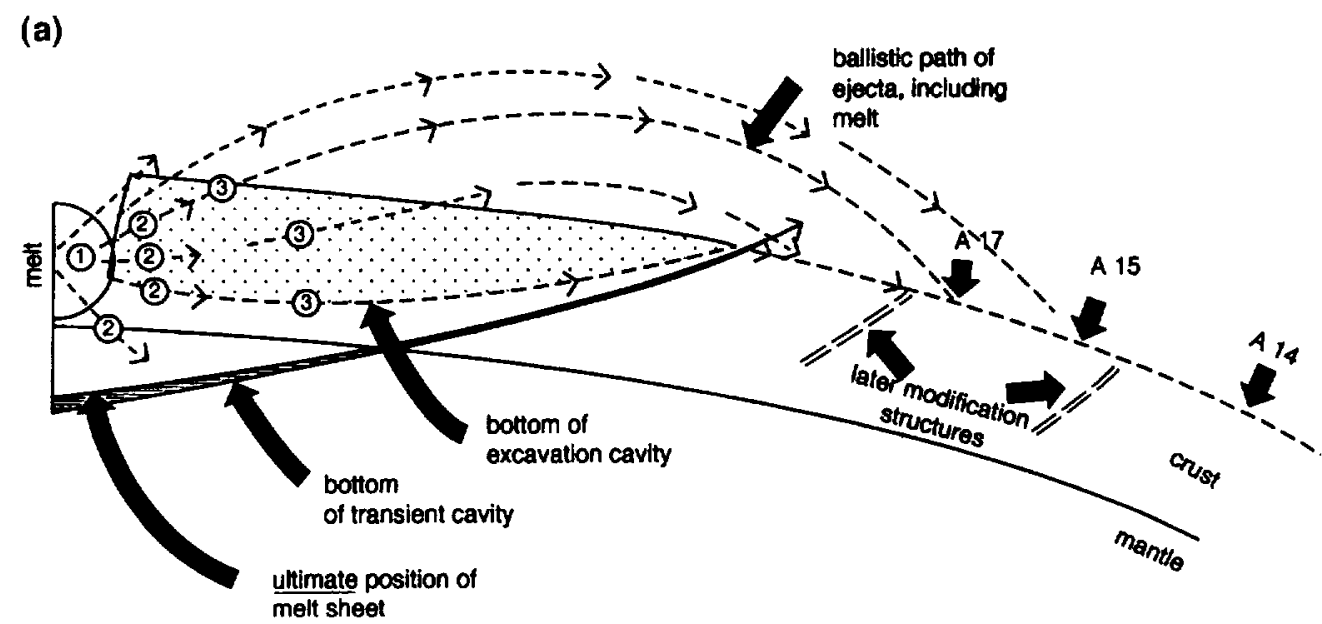

(1) melt zone

(2) highly shocked and comminuted material: mineral fragments?

(3) less shocked and comminuted material: lithic fragments?

(b)

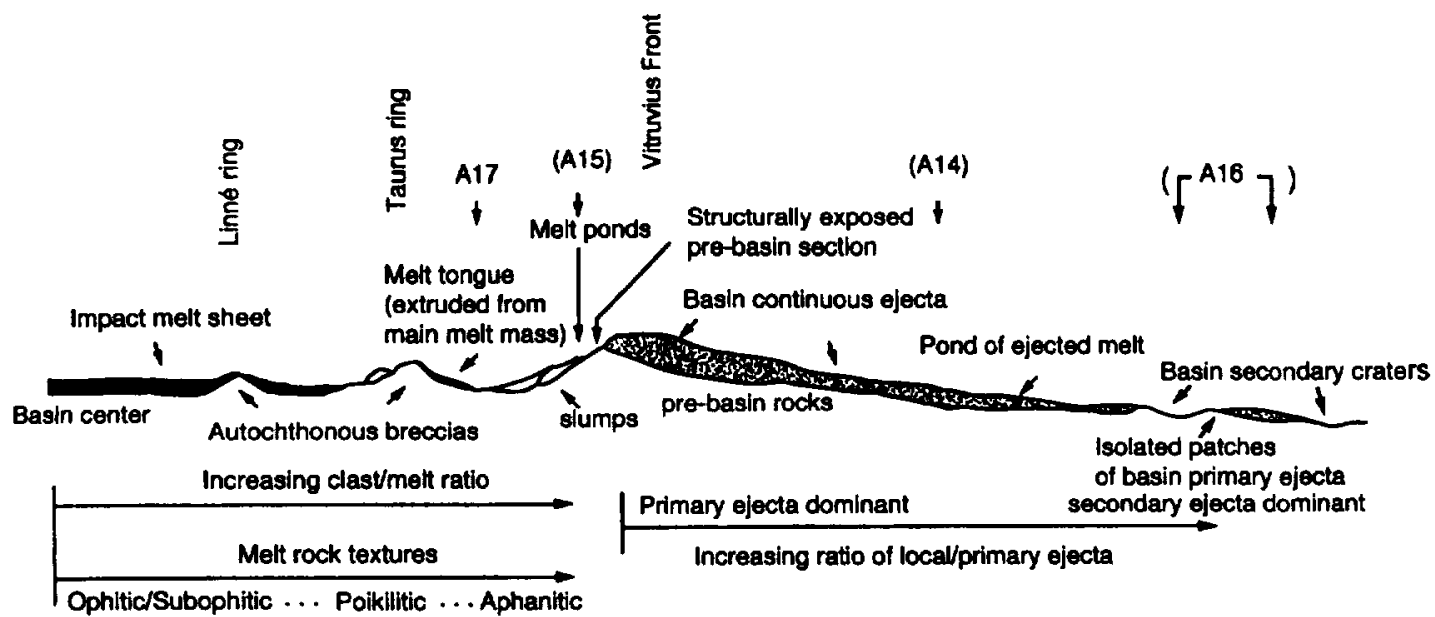

Fig. 2. (a) Model for generation of a large impact structure and its ejecta production and emplacement. The Apollo 17 landing site, shown relative to the Serenitatis basin, lies outside the transient cavity and the melt rocks collected there were not part of a continuous melt sheet that is (presumably) within the main cavity. They are instead from a spillover of some kind. Comparative locations for the Apollo 14 and Apollo 15 sites are relative to the lmbrium basin. (Modified from Spudis, 1993). (b) Relation of Apollo 17 and other highland landing sites to a hypothetical basin structure. showing ejecta types. Apollo 17 site is shown relative to the Serenitatis basin. Comparative locations for the Apollo 14, Apollo 15, and Apollo 16 sites are shown relative to the Imbrium basin. (Modified from Spudis, 1993). 


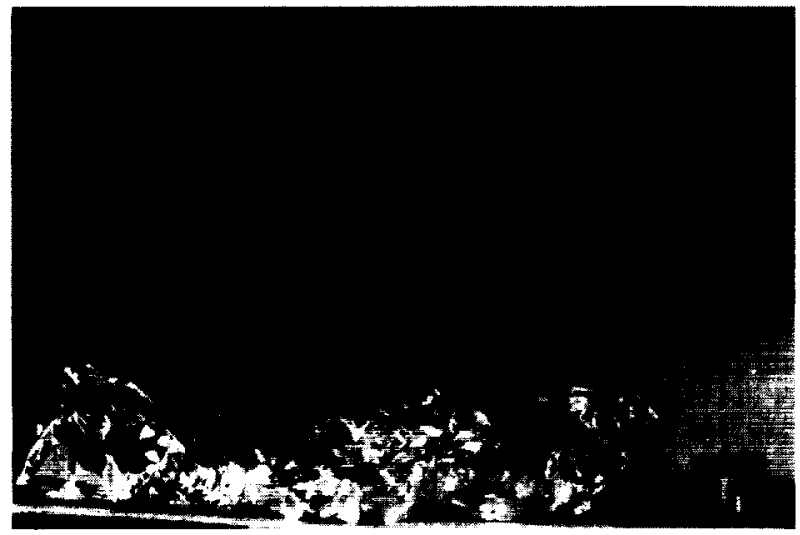

Fig. 3. Poikilitic melt breccia 72435 prior to any dissection, showing prominent clasts, mainly angular, in a fine-grained, irregularly vesicular melt phase. Scale bar and cube side is $1 \mathrm{~cm}$. NASA JSC photograph S-73-16187.

Minerals crystallized from impact melts behave similarly to those in igneous rocks. Impact melts are emplaced at or near the surface, and, thus, except for hypothesized very large-scale melts, cool quickly and reproduce mineral features similar to those in volcanic rocks. Thus even fragmentpoor, crystalline impact melts such as 68415 have fairly fine grain sizes, their pyroxenes are in the forbidden region of the quadrilateral, and their olivines (if present) have high calcium (e.g., Helz and Appleman, 1973). Metamorphism, such as that which produced the lunar feldspathic granulites, changes the mineral compositions including minor elements, and reduces or eliminates zoning in grains and differences among grains. Thus calcium in olivines in feldspathic granulites is much lower than in volcanic rocks, but tends to be higher than in olivines in true plutonic igneous rocks (e.g., Cushing et al., 1997).

\section{MINERAL FRAGMENTS, REACTION, AND SAMPLE SELECTION}

Mineral fragments immersed in melt breccias react with the melt (e.g., Thornber and Huebner, 1980). In an extreme case, all mineral fragments are resorbed and annihilated. In the Apollo 17 Serenitatis melt breccias, mineral-melt reactions in coarse-grained samples have reduced and distorted the original mineral population. Pyroxenes have been preferentially digested such that in many samples little fragmental pyroxene is present at all, and iron-rich mafic minerals and sodium-rich plagioclases are rare (e.g., Simonds, 1975; Dymek et al., 1976). Both pyroxenes and olivines are digested more than the plagioclases. Mineral reaction that modified at least the major element compositions is extensive in those samples with a coarser-grained groundmass, e.g., in sample 76015 , olivines are zoned in $\mathrm{Mg}-\mathrm{Fe}$ by reaction up to at least $750 \mu \mathrm{m}$ into mineral fragments (Ryder, 1984a); plagioclases show considerably less reaction effect. In the present study we have concentrated our efforts on melt breccias that have a finer-grained groundmass, but even in these the smallest fragmental grains show some zoning caused by reaction with the melt (i.e., the zoning is concentric in the grain as it now is, not crosscut as relict zoning) (Fig. 5). None of the Apollo
17 Serenitatis melt breccia samples is as fine-grained as the Apollo 15 black and white melt breccias, and so this reaction problem is more extensive in the former.

We have analyzed mainly the larger grains in the Serenitatis melt breccias but have also analyzed many small grains to investigate possible zoning and reaction and to find out the composition of groundmass grains (i.e., those crystallized from the impact melt itself) towards which reactions would proceed. To avoid analytical artifacts such as secondary fluorescence and edge effects, we analyzed points at least $15 \mu \mathrm{m}$ from grain boundaries (see Microprobe methods), and, thus, grains smaller than about $30 \mu \mathrm{m}$ were analyzed only to assess what the equilibrium composition would be. Few individual mineral grains are as large as a millimeter, and most of the fragments analyzed are between 50 and 300 $\mu \mathrm{m}$ across.

We chose to study samples $72435,76035,76295,76315$, and 77115, which are among the finest-grained and most fragment-rich of the Apollo 17 Serenitatis melt breccias. All these samples are petrographically and chemically wellcharacterized; descriptions are available in the Apollo 17 sample catalogs (Ryder, 1993; Meyer, 1994). All but 76035 were chipped from boulders ranging from one meter to many meters in long dimension. Some of the fragmental grains analyzed are angular and others are well-rounded; some show evident shock features, and others appear homogeneously crystalline. Such features reflect varied differences in the histories of fragments prior to and after being immersed in the melt but have not been used to distinguish populations in this study.

\section{ELECTRON MICROPROBE METHODS}

The data used in this paper were acquired with electron microprobes over a period of years and with some variation in analytical conditions, standards, and operators, at the Universität Muinster, the Johnson Space Center, and the University of Hawaii. In nearly all cases, the beam current was in the range of $20-50 \mathrm{nA}$, the accelerating potential was $15 \mathrm{keV}$, and data were reduced using ZAF corrections. The counting time varied according to the counting statistics required. In almost all cases a focussed beam with a diameter of 2$3 \mu \mathrm{m}$ was used. For some of the plagioclase analyses, the beam was rastered over a 10 or $20 \mu \mathrm{m}$ square area, but comparative analyses using a stationary beam showed no significant $\mathrm{Na}$ loss. A variety of standards was used, including natural minerals and synthetic glasses, as appropriate for the element and phase being analyzed. Particular attention was paid to obtaining the appropriately-placed background counts that are crucial to accuracy if not to precision. Representative analyses for olivines, pyroxenes, and plagioclases are given in Tables $1-3$, respectively.

For olivine fragments, we analyzed $\mathrm{Mg}, \mathrm{Fe}, \mathrm{Mn}$, and $\mathrm{Si}$ using count times of $10-25 \mathrm{sec}$. We used longer count times on peaks and backgrounds for the minor elements $\mathrm{Al}, \mathrm{Ti}, \mathrm{Ca}$, and $\mathrm{Cr}$, typically $40-120 \mathrm{sec}$. Our conditions usually resulted in analytical precision of about $0.01-0.02 \mathrm{wt} \%$ (absolute) for the minor elements, according to counting statistics and to repeat analyses. There is a potential analytical problem for the important element $\mathrm{Ca}$ from secondary fluorescing of adjacent phases. Empirical data and analysis of Dalton and Lane (1996) shows that for our conditions and phases, and analyzing at least $15 \mu \mathrm{m}$ from any grain boundaries, secondary fluorescence will not have increased the calculated abundances of $\mathrm{Ca}$ in any olivine by more than $0.01 \mathrm{wt} \%$. That is less than or similar to the counting uncertainties and of no consequence for our inferences. In some runs $\mathrm{Ni}$ was analyzed but not at a sufficient counting time to provide better uncertainties than upper limits of a few hundred ppm; no olivines were found that had Ni detectable at such abundances. Replicate analyses were made on many olivine 
(a)

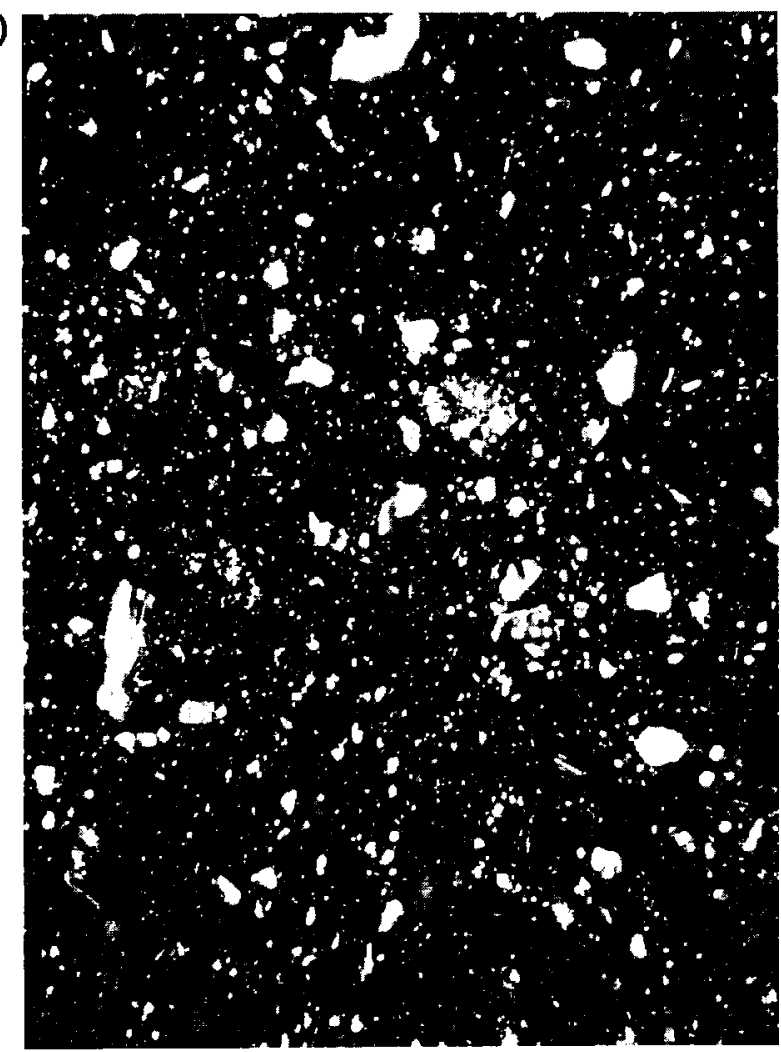

(b)

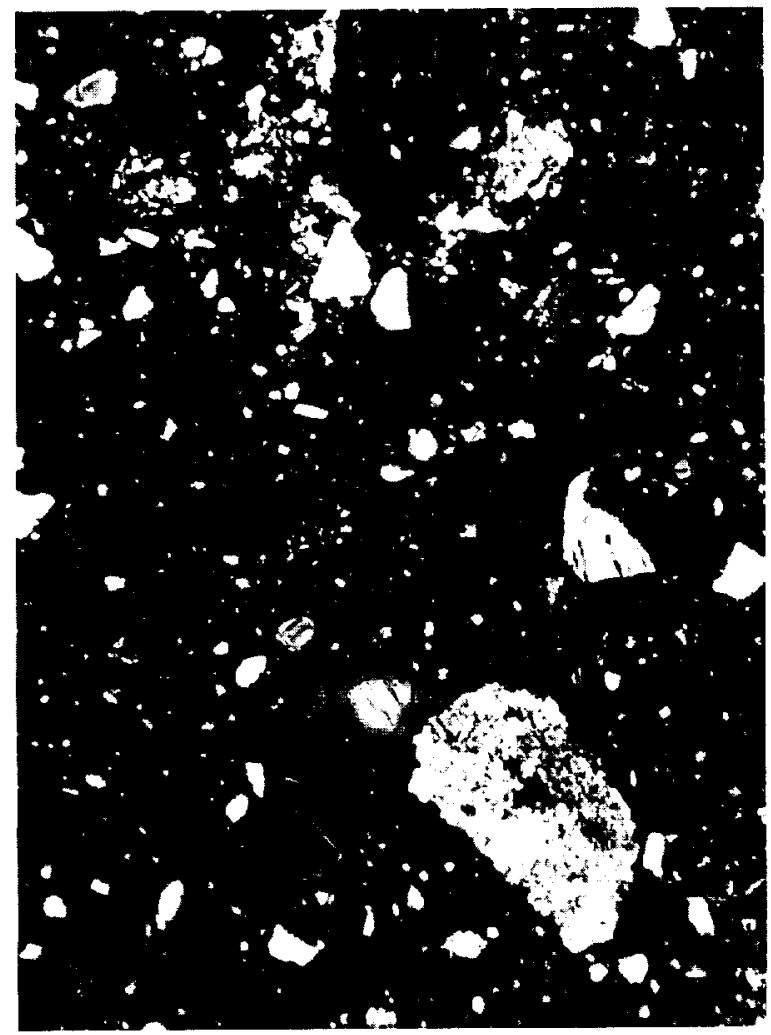

Fig 4. (a) Photomicrograph of thin section 72435,60). Crossed polarizers. Width about $4 \mathrm{~mm}$. Many small lithic fragments and many more even smaller mineral fragments are visible in a tinegrained groundmass. The plagioclase clast in middle left hat a prominent overgrowth rim. (b) Photomicrograph of thin section 77115.55 . (a)

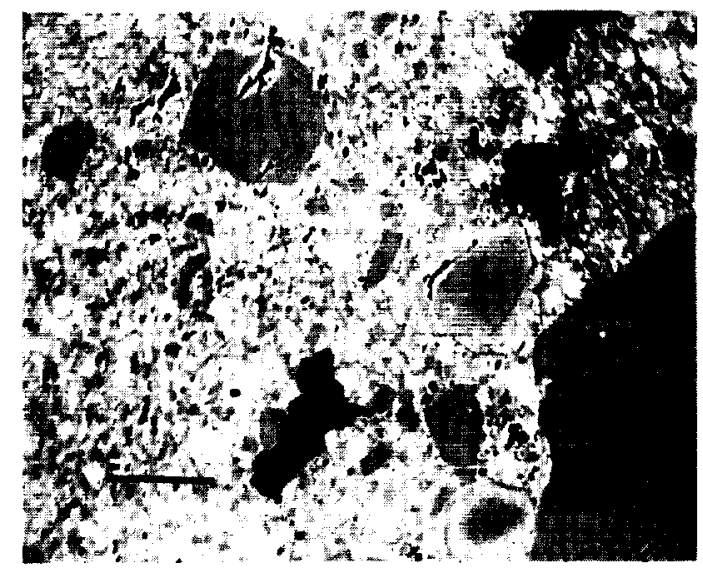

(b)

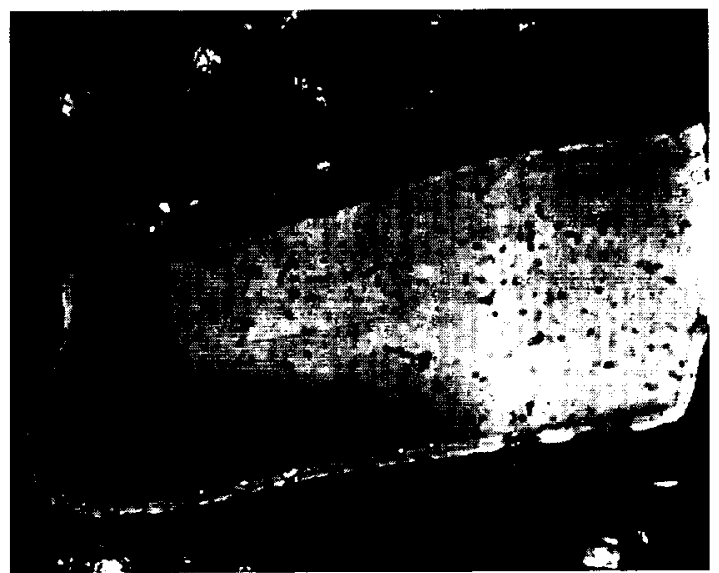

Fig. 5. (a) Backscattered electron image of thin section 76035,27 Long scale har is $100 \mu \mathrm{m}$. Darkest gray, unrimmed fragments are plagioclases. Other gray fragments with paler-gray (more iron-rich) reaction rims are olivines. Groundmass consists of small plagioclases and olivine fragments (re-equilibrated) and a plagioclase-pyroxenemelt phase. Black areas are holes and cracks in the thin section. (b) Photomicrograph of thin section 76035,27, showing zoned plagioclase fragment with overgrowth rim of groundmass pligioclase Crossed polarizers, about $200 \mu \mathrm{m}$ width of view

points and more than one analysis on many individual fragments To assess consistency, accuracy, and precision, analyses of the wellcharacterized and homogeneous olivines from the Marjalahti and Springwater pallasites were made under the same conditions during the same runs. However, $\mathrm{Cr}$ appears to be somewhat varied within a given pallasite (Ryder, $1984 \mathrm{~b}$ ).

For pyroxene fragments, we analyzed the same elements as for olivine. The greater abundances of the elements $\mathrm{Al}$. Ti, $\mathrm{Ca}$. and $\mathrm{Cr}$ in pyroxenes than in olivines obviated the actual need for such long count times or such cautious background location to obtain the data, but because olivines and pyroxenes were mainly analyzed in the same run. the same conditions and count times were often used. Many fewer pyroxenes than olivines are present in the samples, and in some samples we did not analyze pyroxenes.

For plagioclase fragments, we analyzed Si, $\mathrm{Al}, \mathrm{Ca}$, and $\mathrm{Na}$ in routine fashion. We used longer count times on peaks and back-

Crossed polarizers. Width about $2 \mathrm{~mm}$. The sample contains abundant small mineral and lithic clasts. Some olivine fragments have reaction rims. 
Table 1. Representative analyses of olivine fragments in wt.\%.

\begin{tabular}{|c|c|c|c|c|c|c|c|c|c|c|c|c|}
\hline Section & 76295,81 & 77115,55 & 72435,59 & 77115,55 & 72435,59 & 77115,55 & 72435,59 & 76315,10 & 77115,55 & 76035,27 & 76035,27 & 76035,27 \\
\hline Point & 8 & 41 & 1 & 26 & 83 & 46 & 9 & 24 & 30 & 2 & 7 & 38 \\
\hline $\mathrm{SiO}_{2}$ & 37.4 & 37.0 & 37.9 & 38.6 & 39.0 & 38.7 & 38.9 & 40.5 & 40.4 & 40.0 & 40.7 & 40.7 \\
\hline $\mathrm{THO}_{2}$ & 0.044 & 0.089 & 0.051 & 0.012 & 0.051 & 0.026 & 0.016 & 0.027 & 0.000 & 0.163 & 0.032 & 0.028 \\
\hline $\mathrm{Ab}_{2} \mathrm{O}_{3}$ & & 0.020 & 0.016 & 0.015 & 0.045 & 0.026 & 0.007 & & 0.028 & 0.102 & 0.298 & 0.055 \\
\hline FeO & 27.5 & 25,4 & 21.0 & 17.6 & 16.9 & 15.4 & 14.7 & 11.2 & 8.9 & 8.0 & 7.4 & 6.9 \\
\hline MnO & 0.268 & 0.258 & 0.234 & 0.190 & 0.121 & 0.149 & 0.162 & 0.042 & 0.075 & 0.110 & 0.088 & 0.086 \\
\hline $\mathbf{M} \mathbf{O}$ & 34.4 & 35.9 & 39.7 & 42.8 & 43.2 & 44.6 & 45.2 & 48.8 & 49.9 & 50.9 & 51.0 & 52.2 \\
\hline $\mathrm{CaO}$ & 0.097 & 0.271 & 0.070 & 0.134 & 0.124 & 0.044 & 0.013 & 0.088 & 0.079 & 0.109 & 0.185 & 0.043 \\
\hline $\mathrm{Cr}_{2} \mathrm{O}_{3}$ & 0.043 & 0.110 & 0.079 & 0.069 & 0.073 & 0.109 & 0.037 & 0.068 & 0.129 & 0.175 & 0.040 & 0.129 \\
\hline Sum & 99.8 & 99.0 & 99.0 & 99.4 & 99.5 & 99.0 & 99.1 & 100.8 & 99.5 & 99.6 & 99.8 & 100.1 \\
\hline Fo mol \% & 69.0 & 71.6 & 77.1 & 81,2 & 82.0 & 83.8 & 84.5 & 88.6 & 90.9 & 91.9 & 92.5 & 93.1 \\
\hline
\end{tabular}

grounds for the minor elements $\mathrm{K}, \mathrm{Fe}$, and $\mathrm{Mg}$. Counting statistics give uncertainties on the minor elements on the order of $0.01-$ $0.02 \mathrm{wt} \%$, consistent with replicate analyses and analyses of pure anorthite glass. Secondary fluorescence from adjacent phases, a problem for $\mathrm{Fe}$ in plagioclase (Longhi et al.. 1976), was minimized by analyzing at least $50 \mu \mathrm{m}$ from grain boundaries.

We made analyses of all three silicate phases in one representative thin section of each sample, except for 72435 for which we used two serial thin sections. The thin sections ranged in area from about $1 \mathrm{~cm}^{2}$ to about $3 \mathrm{~cm}^{2}$. We tried to analyze all of the fragments that were larger than $50 \mu \mathrm{m}$ in a thin section. In all, we made about four hundred and fifty analyses of olivine, eighty analyses of pyroxene, and four hundred analyses of plagioclase grains in these rocks, most of which were petrographically obvious as fragments.

\section{MINOR ELEMENT DATA IN COMPARATIVE ROCKS}

Bersch (1990) and Bersch et al. (1991) made high precision electron microprobe analyses for minor elements of olivine and pyroxene in many lunar highlands igneous rocks. Other reliable analyses for some minor elements in olivines in such rocks have been made by Steele and Smith (1975), Smith et al. (1980), and Ryder (1992a). We also compiled our own unpublished data for olivines in lunar rocks, including mare basalts.

While a wide variety of electron microprobe data is available for terrestrial olivines from varied rocks and environments, little of it is of adequate precision for most of the minor elements. Simpkin and Smith (1970) reviewed microprobe data for $\mathrm{CaO}$, and we culled some reliable data from a number of papers published since then (e.g., Garcia, 1996, and Baker et al., 1996, for basalts from Hawaii; Taylor et al., 1994, for boninites; Renner et al., 1994, for komatiites; and Donaldson, 1975a,b, for the hypabyssal Rhum intrusion). We analyzed olivines in several samples from the Stillwater and Bushveld intrusions ourselves using the same conditions as those for olivines in our Apollo 17 Serenitatis melt breccias, to provide some reliable data on olivine from plutonic rocks. Some data obtained using ion microprobe techniques is available for mantle-derived olivines (e.g., Hervig et al., 1980; Köhler and Brey, 1990; Hauri and Hart, 1994). For pyroxenes in lunar and terrestrial rocks, a large amount of reliable data is available because the abundances of the minor elements of interest are great enough that special conditions for analysis are not required.

The main source of data for minor elements in lunar plagioclases is McGee (1993, and pers. commun.), who analyzed ferroan anorthosites, and Hansen et al. (1979), who analyzed a variety of lunar igneous rocks. We could not use much other published data for lunar plagioclases because they are of unstated precision and the analyses were not made with the intention of precise minor element determination. We also use our own unpublished data for a variety of Mg-suite, KREEP, mare basalt, and anorthositic rocks. We have not made comparisons with terrestrial rocks because the different oxidation state of iron appears to be an important factor (Longhi et al., 1976), and because of the grossly different ranges of $\mathrm{Na}$ content.

Few precise minor element data exist for minerals in lunar rocks that are not endogenous igneous rocks, such as feldspathic granulites and crystalline impact melt rocks that are coarse-grained enough to have been (in principle) the source of mineral fragments analyzed in this study. However, enough adequate data exists for some elements, such as $\mathrm{CaO}$ in olivines, for the comparative purposes of the present study (e.g., Helz and Appleman, 1973; Cushing et al., 1997).

\section{DATA SELECTION AND PRESENTATION}

This study has produced a large amount of data, creating n-dimensional information. Representative individual spot analyses are presented in Tables 1-3 (olivine, pyroxene, and plagioclase, respectively). We present all the analyses in the form of two-dimensional plots of individual minor elements against the major element composition (e.g., mol\% Fo for olivines) of the phase. For pyroxenes we also plot the data on the pyroxene quadrilateral on which the endmembers are the pure $\mathrm{Mg}, \mathrm{Ca}$, and $\mathrm{Fe}$ components.

The Apollo 17 Serenitatis melt breccia data are drawn on diagrams with the fields for lunar igneous rocks for comparison. Some of these plots show generalized fields for crystalline impact melts and feldspathic granulites from literature data. We show comparative data for the Apollo 15 black and white breccias that are strong candidates for Imbrium melt breccia (Ryder and Bower, 1977) and for terrestrial igneous rocks as appropriate. Replicated standards such as Marjalahti olivine are shown to indicate analytical precision. Different symbols are used for the different individual samples of Serenitatis melt breccia so that comparison can be made among samples. The diagrams do not identify multiple analyses on single grains, and they do not distinguish petrographically different types of grains, such as shocked and unshocked or angular and rounded.

Except for Fig. 6, we plot only analyses for grains larger than $50 \mu \mathrm{m}$, and most are for grains larger than $100 \mu \mathrm{m}$. In Fig. 6, for sample 77115, analyses near grain edges (practi- 
Table 2. Representative analyses of pyroxene fragments in wt.\%.

\begin{tabular}{|c|c|c|c|c|c|c|c|c|c|c|c|c|}
\hline Section & 76295,81 & 72435,60 & 76295,81 & 76315,108 & 72435,60 & 76295,81 & 76295,81 & 76315,108 & 77115,55 & 72435,60 & 72435,60 & 76295,81 \\
\hline Point & 13 & 1 & 32 & 45 & 7 & 37 & $\mathbf{3 0}$ & 40 & 54 & 10 & 3 & 38 \\
\hline $\mathrm{SiO}_{2}$ & 56.1 & 53.4 & 50.7 & 55.0 & 50.5 & 50.2 & 53.3 & 53.4 & 51.1 & 50.4 & 49.7 & 51.8 \\
\hline $\mathrm{TiO}_{2}$ & 0.36 & 0.80 & 1.76 & 0.25 & 1.40 & 2.78 & 0.31 & 0.38 & 0.46 & 0.55 & 1.46 & 0.89 \\
\hline $\mathrm{Ab}_{\mathbf{6}} \mathrm{O}_{3}$ & 0.88 & 1.30 & 2.39 & 1.17 & 1.97 & 2.89 & 1.81 & 0.31 & 1.56 & 0.83 & 1.87 & 1.50 \\
\hline $\mathrm{FeO}$ & 9.7 & 12.1 & 6.4 & 12.7 & 7.7 & 8.4 & 13.6 & 18.9 & 18.0 & 20.3 & 15.5 & 16.6 \\
\hline MnO & 0.16 & 0.23 & 0.18 & 0.19 & 0.17 & 0.14 & 0.32 & 0.36 & 0.32 & 0.34 & 0.26 & 0.27 \\
\hline $\mathrm{MgO}$ & 31.7 & 28.6 & 15.2 & 28.8 & 15.5 & 15.8 & 23.8 & 23.4 & 19.9 & 20.8 & 13.9 & 13.3 \\
\hline $\mathrm{CaO}$ & 0.70 & 1.91 & 20.54 & 1.42 & 21.44 & 18.39 & 5.77 & 2.66 & 6.70 & 5.88 & 15.76 & 16.42 \\
\hline $\mathrm{Cr}_{2} \mathrm{O}_{3}$ & 0.42 & 0.41 & 0.62 & 0.68 & 0.62 & 0.55 & 0.73 & 0.28 & 0.69 & 0.38 & 0.53 & 0.54 \\
\hline Sum & 100.0 & 98.7 & 97.8 & 100.2 & 99.2 & 99.0 & 99.6 & 99.7 & 98.8 & 99.4 & 99.0 & 101.3 \\
\hline $\mathbf{M g}^{\prime}$ & 85.3 & 80.9 & 80.8 & 80.2 & 78.2 & 77.1 & 75.8 & 68.9 & 66.4 & 64.7 & 61.6 & 58.9 \\
\hline En mol \% & 84.2 & 77.9 & 45.2 & 78.0 & 43.9 & 46.8 & 66.9 & 65.2 & 57.2 & 57.2 & 41.0 & 38.7 \\
\hline Wo mol \% & 1.3 & 3.7 & 44.0 & 2.8 & 43.8 & 39.3 & 11.7 & 5.3 & 13.8 & 11.6 & 33.3 & 34.3 \\
\hline Fs mol \% & 14.5 & 18.4 & 10.8 & 19.2 & 12.2 & 13.9 & 21.4 & 29.5 & 29.0 & 31.2 & 25.6 & 27.0 \\
\hline
\end{tabular}

cally, 25-50 $\mu \mathrm{m}$ ), analyses of grains smaller than $50 \mu \mathrm{m}$, and analyses of grains in three size classes larger than 50 $\mu \mathrm{m}$ are distinguished. Some olivine grains in the 50-100 $\mu \mathrm{m}$ range, as well as some near-edge analyses, are magnesian and did not significantly equilibrate their $\mathrm{Mg}$-Fe towards the groundmass composition, as represented by the tiniest grains. Chao et al. (1975) found reaction/partial re-equilibration for $\mathrm{Mg}-\mathrm{Fe}$ in rims about $30 \mu \mathrm{m}$ wide on olivine fragments from this rock, with the very edge approaching the groundmass composition. Some small olivine fragments in our breccias, both $\mathrm{Fe}$ - and $\mathrm{Mg}$-rich, have low $\mathrm{Ca}$ and $\mathrm{Cr}$ contents and are not equilibrated to the groundmass composition. While the $\mathrm{Ti}$ and $\mathrm{Al}$ data are by themselves not compelling in this regard, minor element diffusion rates in olivine are probably similar to or less than Mg-Fe diffusion (e.g., Jurewicz and Watson, 1988). Thus, we are confident that in this sample most grains larger than $100 \mu \mathrm{m}$, and probably all those larger than $50 \mu \mathrm{m}$, have preserved primary, relict compositions for the elements analyzed.

The composition of groundmass plagioclases in 72435 is widely varied, from $A b_{5-18}$ according to Dymek et al. (1976). Other Serenitatis melt breccia samples appear to be similar (e.g., Simonds, 1975). Thus, continuous equilibration of groundmass plagioclases with melt did not occur; diffusion of elements in plagioclases is much slower than it is in mafic phases. This suggests that plagioclase fragments did not equilibrate with the melt either. We did not analyze plagioclase fragments in 72435 , but analyses across boundaries of plagioclase fragments in our other samples show little or no evidence of reaction with the melt; in nearly all cases a distinct boundary separates a homogenous interior from a distinct overgrowth rim or other groundmass phases (Fig. 5). We did not analyze very small grains or obvious groundmass grains. Thus, we are confident that nearly all our analyses are of relict, unchanged plagioclase fragments that reflect the primary mineral compositions of target rocks prior to the Serenitatis event.

\section{OLIVINE MINERAL FRAGMENTS IN SERENITATIS MELT BRECCIAS}

Our data for olivine mineral fragments and comparative data are presented in Figs. 6-9, with representative analyses as Table 1. There is a wide range of compositions for the major elements, from $\mathrm{Fo}_{94}$ to $\mathrm{Fo}_{67}$, much as shown in other studies of these melt breccias (Dymek et al., 1976). However, the range is slightly wider at both extremes than previously reported. There is also a wide range in minor element abundances, and except for $\mathrm{MnO}$ (not shown), there is no simple binary correlation of minor with major element abundances. The consistent $\mathrm{Mn} / \mathrm{Fe}$ ratio shows that all of these olivines are consistent with a lunar origin, that is, there are no meteoritic relics. The high $\mathrm{Cr}$ content of most olivines is also consistent with a lunar origin.

The composition of groundmass olivine in these melt breccia samples is about $\mathrm{Fo}_{66-72}$ (e.g., Simonds 1975; Dymek et al., 1976; Chao et al., 1975). Our own analyses show a cluster of compositions about $\mathrm{Fo}_{68-72}$ (e.g., 77115, Fig. 6). Some fragmental grains are as Fe-rich as this, but none are more Fe-rich.

Table 3. Representative analyses of plagioclase fragments in wt.\%.

\begin{tabular}{|c|c|c|c|c|c|c|c|c|c|c|c|c|}
\hline Section & 76035,27 & 76295,81 & 76035,27 & 76315,10 & 76035,27 & 76295,81 & 76295,81 & 76035,27 & 76295,81 & 76315,10 & 76315,10 & 76295,81 \\
\hline Polnt & 77 & 26 & 25 & 17 & 27 & 27 & 35 & 91 & 36 & 8 & 16 & 34 \\
\hline $\mathrm{SiO}_{3}$ & 43.4 & 44.6 & 44.1 & 45.4 & 45.5 & 46.2 & 46.5 & 46.0 & 47.3 & 48.2 & 48.7 & 50.9 \\
\hline $\mathbf{A h}_{2} \mathbf{O}_{3}$ & 36.8 & 36.2 & 35.0 & 35.8 & 34.4 & 35.1 & 34.5 & 34.6 & 34.4 & 33.3 & 33.0 & 31.5 \\
\hline FeO & 0.124 & 0.179 & 0.070 & 0.140 & 0.092 & 0.164 & 0.151 & 0.158 & 0.144 & 0.150 & 0.120 & 0.223 \\
\hline $\mathrm{MgO}$ & 0.036 & 0.050 & 0.128 & 0.090 & 0.123 & 0.033 & 0.104 & 0.040 & 0.066 & 0.120 & 0.090 & 0.092 \\
\hline $\mathrm{CaO}$ & 20.3 & 19.1 & 19.1 & 18.6 & 18.2 & 17.8 & 17.6 & 17.7 & 17.3 & 16.2 & 15.8 & 14.5 \\
\hline $\mathrm{Na}_{3} \mathrm{O}$ & $\mathbf{0 . 3 1 0}$ & 0.600 & 0.690 & 0.850 & 1.061 & 1.180 & 1.290 & 1.340 & 1.510 & 1.800 & 1.640 & 2.450 \\
\hline $\mathrm{K}_{2} \mathrm{O}$ & 0.000 & 0.060 & 0.062 & 0.060 & 0.047 & 0.160 & 0.140 & 0.107 & 0.230 & 0.460 & 1.000 & 0.990 \\
\hline Sum & 100.9 & 100.8 & 99.1 & 100.8 & 99.6 & 100.7 & 100.4 & 99.9 & 101.0 & 100.3 & 100.3 & 100.7 \\
\hline An mol \% & 97.3 & 94.3 & 93.5 & 92.0 & 90.2 & 88.5 & 87.6 & 87.4 & 85.2 & 81.0 & 79.1 & 72.1 \\
\hline Ab mol $\%$ & 2.7 & 5.4 & 6.1 & 7.6 & 9.5 & 10.6 & 11.6 & 12.0 & 13.5 & 16.3 & 14.9 & 22.0 \\
\hline Or mol \% & 0.0 & 0.4 & 0.4 & 0.4 & 0.3 & 0.9 & 0.8 & 0.6 & 1.4 & 2.7 & 6.0 & 5.9 \\
\hline
\end{tabular}



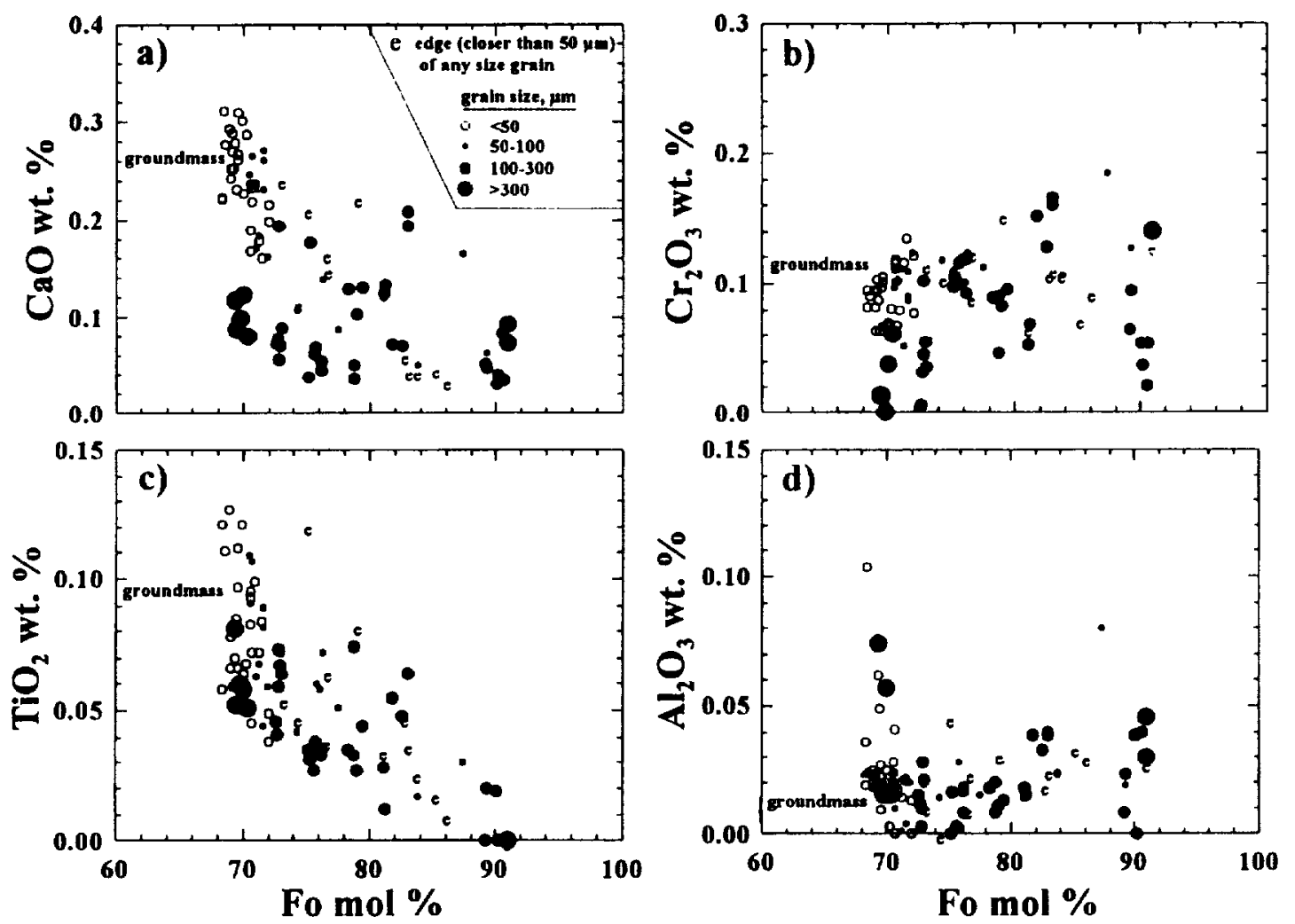

Fig. 6. Abundances of minor elements vs. forsterite content for olivine fragments in thin section 77115, 55. Varied symbols represent different grain sizes.

There are some differences in the analyzed olivine sample populations among rock samples, even for major elements (Figs. 6-9). These could result from inadequate surveying (i.e., the differences might disappear if a larger number of olivines from each sample were analyzed); from real differences in the actual populations in each rock representing differences among rocks in the pick-up zone; or possibly from differential dissolutions related to post-impact thermal histories. The two serial thin sections of 72435 show similar sample populations (Fig. 7), which have major element ranges similar to that reported from this rock by Dymek et al. (1976), though not extending to quite such magnesian compositions. The conspicuous abundance of Fe-rich olivine we found in 76295 similarly appears in the data of Phinney (1981). This suggests that our surveying is adequate to at least represent the thin section scale and probably the hand sample scale. Differences were found in plagioclase fragment populations among samples from our test example of the Mistastin Lake structure (McCormick et al., 1989), although admittedly those samples were from comparatively widespread locations in that melt. We can see no reasonable way that differential dissolution could produce the observed differences, for instance the preferential preservation of a group of high $\mathrm{Mg}-\mathrm{Ca}-\mathrm{Cr}-\mathrm{Al}$ olivines in 76035 and the complete lack of $\mathrm{Mg}$-olivines in 76295 . We infer that the fragment populations sampled in thin sections represent differences in the fragment populations in the breccias at the scale of at least a few centimeters. Stockstill and Ryder (1995) found small but significant differences in bulk chemical com- position among Serenitatis melt breccia samples that reflect differences among both fragment populations and melt compositions.

About half of the olivine fragments have compositions generally similar to the ranges of those in known lunar $\mathrm{Mg}$ suite rocks, a loose grouping of rocks that are certainly not all consanguinous. Possible source rocks with appropriate mineral compositions would include troctolites such as 76535 , spinel-bearing troctolites from 15445, dunite 72415 , olivine-norites such as a fragment in 15306 , and feldspathic lherzolite 67667 (Bersch et al., 1991; Smith et al., 1980). However, the other half of the olivine fragment population is unlike those in any known lunar rock types.

At a given Fo content, the $\mathrm{CaO}$ contents of all the olivine fragments are lower than those in olivines in basalts typically extruded on both Earth and the Moon, generally higher than those in terrestrial plutonic rocks such as in the Bushveld and Stillwater intrusions, and similar to those in shallow intrusions such as Rhum (Fig. 8). Such $\mathrm{CaO}$ contents ( $\sim 0.1$ $w t \%$ ) are similar to those derived from hot terrestrial mantle, such as the San Carlos olivines (e.g., Baker et al., 1996), but are also found in dunite $72415 / 7$ which has zoned olivines and is extremely unlikely to be a mantle sample (Ryder, 1992a). This more extensive dataset remains consistent with the conclusion of Ryder (1984a) that most of the olivine fragments in the Serenitatatis poikilitic melt breccias are derived from fairly rapidly cooled, presumably hypabyssal, intrusions; others are deeper plutonic. None apparently represent the lunar mantle. 

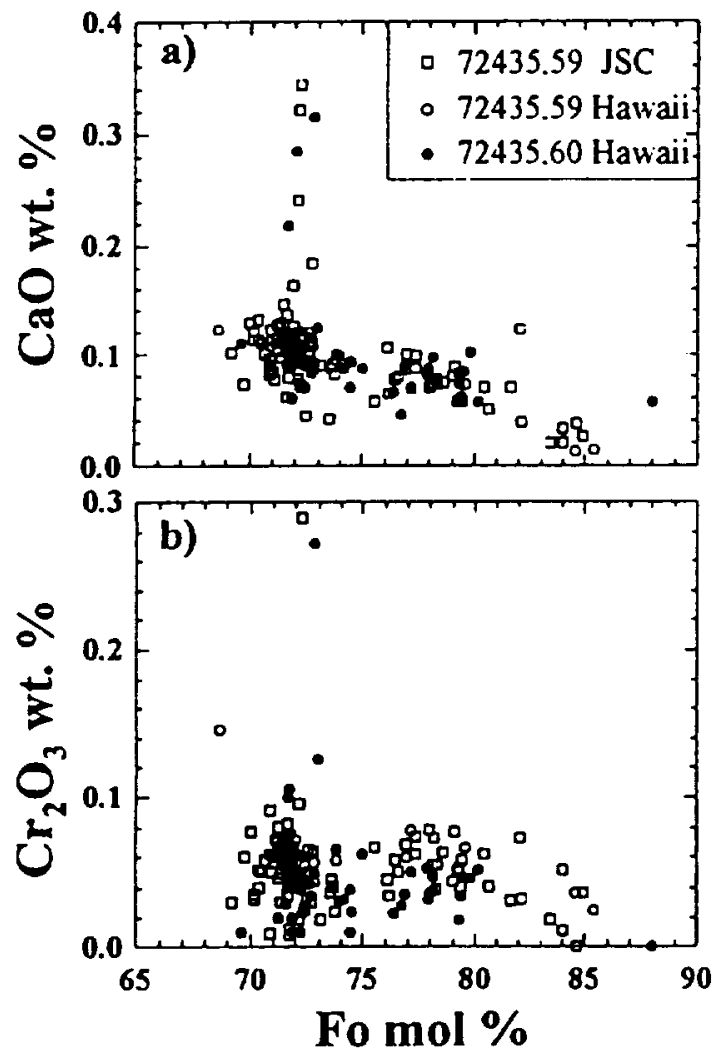

Figure 7. Abundances of minor elements vs. forsterite content for olivine fragments in two thin sections of 72435. Different symbols represent different symbols and institute where analysis was performed. JSC $=$ Johnson Space Center.

Two broad compositional types of olivine in these Serenitatis melt breccias are particularly distinct from those in known lunar rocks. One is forsteritic ( $\left.\mathrm{Fo}_{87-94}\right)$ with comparatively high abundances of $\mathrm{CaO}, \mathrm{Cr}_{2} \mathrm{O}_{3}$, and $\mathrm{Al}_{2} \mathrm{O}_{3}$, but not $\mathrm{TiO}_{2}$. These olivines are particularly common in sample 76035. Some of them have $\mathrm{CaO}$ contents as high as those in lunar and terrestrial volcanic rocks (more than $0.25 \mathrm{wt} \%$ ). They have prominently high $\mathrm{Cr}_{2} \mathrm{O}_{3}$ and $\mathrm{Al}_{2} \mathrm{O}_{3}$ abundances, apparently matched only by olivines in terrestrial komatiites (the database for $\mathrm{Cr}_{2} \mathrm{O}_{3}, \mathrm{TiO}_{2}$, and $\mathrm{Al}_{2} \mathrm{O}_{3}$ in olivines for most terrestrial volcanic rocks is rather poor, but see Baker et al., 1996 for data for Hawaiian basalts ). They might represent some form of early magnesian volcanic activity on an early Moon with a hot mantle, analogous to terrestrial komatiites. Not all of the magnesian olivines have these high minor element abundances; some seem more consistent with troctolites such as the undisputed plutonic, and re-equilibrated, sample 76535 (Gooley et al., 1974; Dymek et al., 1975), or the spinel troctolite fragment in 15445 (Ridley et al., 1973). The significance of lithologies with $\mathrm{mg}^{*}$ as high as 94 will be discussed in a subsequent section.

The other distinctive olivine type is Fe-rich $\left(\mathrm{Fo}_{68-75}\right)$ and tending to high abundances of $\mathrm{CaO}, \mathrm{TiO}_{2}$, and $\mathrm{Al}_{2} \mathrm{O}_{3}$, but not $\mathrm{Cr}_{2} \mathrm{O}_{3}$. The Fe-rich olivine fragments, if they have not been produced by melt reaction (and some are more than $300 \mu \mathrm{m}$ across, e.g., in Fig. 6), represent yet another variety whose $\mathrm{CaO}$ abundances suggest cooling rates marginally faster than typical plutonic rocks. Some of these might represent ancient mare basalt volcanism, but their range of major element variation is much smaller than olivines in typical mare basalts (though perhaps biased by resorption). Further, mare basalts such as the Apollo 15 and the Apollo 12 olivinenormative basalts typically have higher $\mathrm{Cr}_{2} \mathrm{O}_{3}$ (0.2-0.5 wt $\%$ ) than do these olivines, and $\mathrm{NiO}$ in many of them would be detectable under our analytical conditions. Few in any case have $\mathrm{CaO}$ as high as those in mare basalts; some have $\mathrm{CaO}$ almost as low as those in plutonic rocks, though none as low as those in ferroan anorthosites. Thus, a different type of rock, perhaps hypabyssal, must be hypothesized as the source of these fragments. Their Fo contents are within the range needed for or at least permissible as part of a Low$K$ Fra Mauro basalt source ( see subsequent section). At a given Fo content, the range of $\mathrm{CaO}$ may represent a range of cooling rates or equilibration temperatures.

On the basis of the range of major element and minor element abundances, mare basalt olivines appear to be absent from the olivine fragment populations of the Serenitatis melt breccias, e.g, Fig. 8a,d. Fragments consistent with ferroan anorthosite, including relatively mafic varieties such as 60025,62236 , and 62237 , are also missing. Ferroan anorthosite olivines have particularly low $\mathrm{CaO}$ abundances (Fig. 8) as well as low abundances of $\mathrm{Al}, \mathrm{Ti}$, and $\mathrm{Cr}$ (Figs. 8, 9). However, they also have Fe abundances greater than those in the Serenitatis melt breccias, and if this is a resorption/ preservation effect, then such olivines might not be present in a melt breccia even if they were in the pick-up zone. Nonetheless, some olivines more Fe-rich than the groundmass olivines are present, and some large grains might be expected to survive resorption in these fine-grained rocks. Thus we interpret the absence of Fe-rich, Ca-poor olivines as evidence that ferroan anorthosites containing significant olivine were at most a minor part of the excavation zone for the Serenitatis impact.

It is not possible to entirely rule out crystalline impact melts or feldspathic granulites as contributors to the olivine fragment population on the grounds of composition alone. However, the generally low $\mathrm{CaO}$ contents of the olivine fragments strongly suggests that any contributing impact melts must have been fairly slowly cooled varieties such as have so far not been found in the lunar sample collection, and that rapidly-cooled varieties must be no more than a minor contributor. Furthermore, fragments of crystalline impact melts of any grain size are not found as lithic fragments within the Apollo 17 Serenitatis melt breccias. Olivines in known feldspathic granulites are almost all very small, even in the coarse-grained, poikilitic (or poikiloblastic) varieties in which they are rare. Thus we conclude that the olivine fragments are dominantly derived from a suite of rocks that is at least partly similar to the known Mg-suite, but which also includes highlands rocks that have characteristics unlike either the known $\mathrm{Mg}$-suite or the ferroan anorthositic suite.

\section{PYROXENE MINERAL FRAGMENTS IN SERENITATIS MELT BRECCIAS}

Our data for pyroxene fragments and comparative data are summarized in Figs. 10 and 11, with representative analyses as Table 2 . The pyroxenes have diverse compositions 

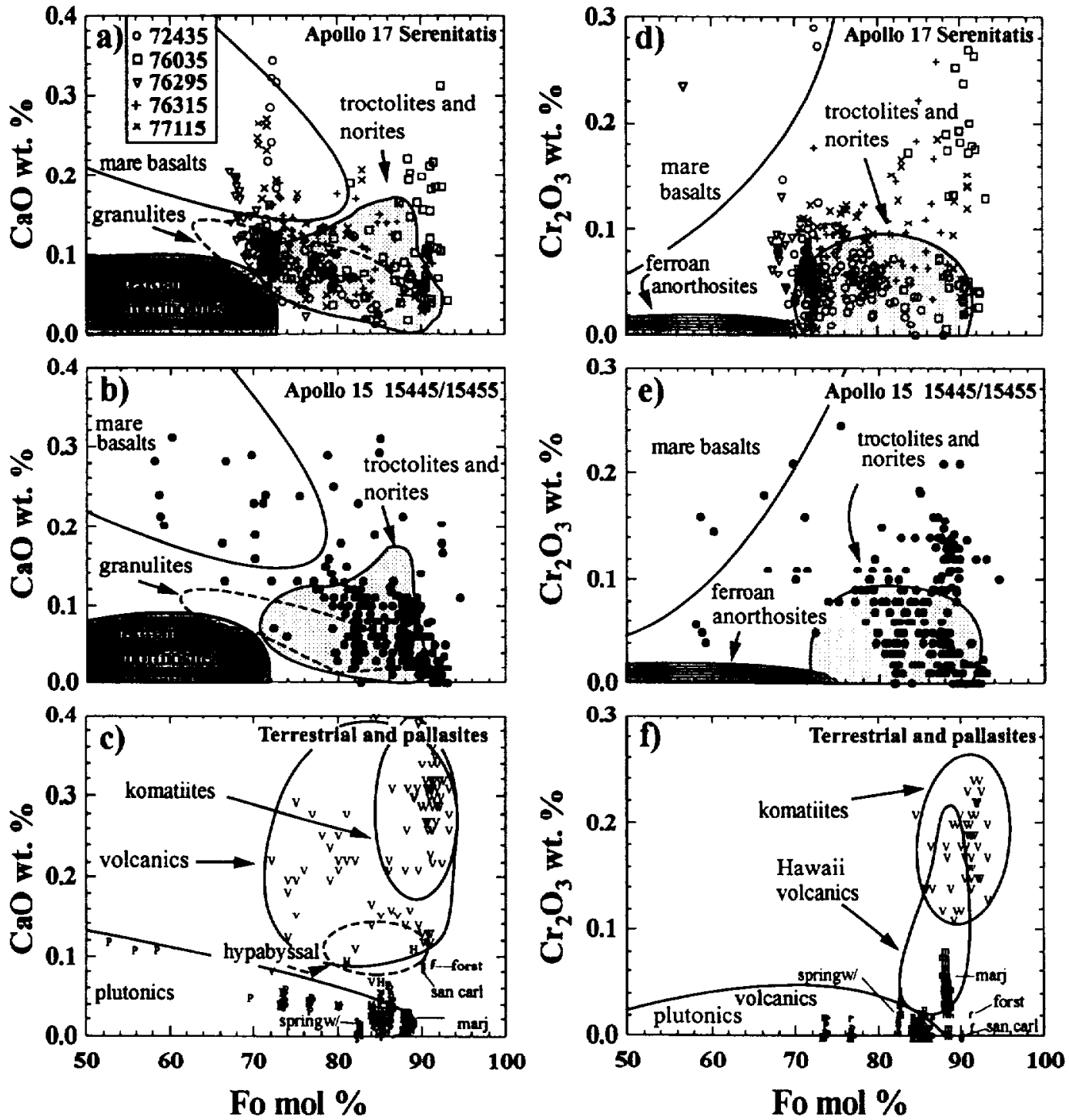

Fig. 8. $\mathrm{CaO}$ and $\mathrm{Cr}_{2} \mathrm{O}_{3}$ vs, forsterite content for olivine fragments larger than $50 \mu \mathrm{m}$ in Serenitatis melt breccias and other olivine samples. For comparative lunar fields, ferroan anorthosites are heayy shade and $\mathrm{Mg}$-suite troctolites and norites are light shade; other fields are unshaded. In (c) and ( $f$ ), olivine standards analyzed for comparison are Marjalahti pallasite ( $m$, marj), Springwater pallasite (s, springw/), San Carlos (c, san carl), and a forsterite ( $f$, forst ). For terrestrial fields shown in (c) and (f), individual analyses are also shown: v, volcanics; $h$, hypabyssal; and p, plutonics.

(Fig. 10) that must represent a variety of sources. There are almost as many fragments of high-Ca pyroxene as of lowCa pyroxene, suggesting that gabbroic sources contribute in a greater proportion than is represented by the pristine igneous rock suite. 76295 also appears to have as much pyroxene as it does olivine, unlike the other samples; the olivine/ pyroxene fragment ratio in 76295 is 0.85 , and in 76315 is 5.2. (Despite its fragment population differences, the bulk chemical composition of 76295 is little different from that of 76315 except for its higher abundance of incompatible elements and $\mathrm{TiO}_{2} ; \mathrm{G}$. Ryder and K. Stockstill, unpubl. data). According to Chao et al. (1975), the fragmental olivine/pyroxene ratio for 77115 is about 2 .

Most of the pyroxene fragments in the Apollo 17 Sereni- tatis melt breccias have major element compositions consistent with a range of $\mathrm{Mg}$-suite norites and gabbros, the dominant pyroxene-bearers among the known pristine highlands igneous rocks (Fig. 10). A few are similar to those in troctolites which contain less pyroxene. Our pyroxene fragment population does not include any as Fe-rich as those in quartz monzodiorite-like rocks or some of the more Fe-rich gabbroic rocks. This absence could be a selective resorption effect. (Such resorption would have occurred at superliquidus temperatures, not during subliquidus cooling, crystallization, and re-equilibration; Simonds, 1975.) The lack of low-Ca pyroxenes similar to those from ferroan anorthosites $\left(E n_{50-70} W_{o_{<3}}\right)$ cannot have the same explanation, because other pyroxenes as $\mathrm{Fe}$-rich as that, but with higher $\mathrm{Ca}$, are 

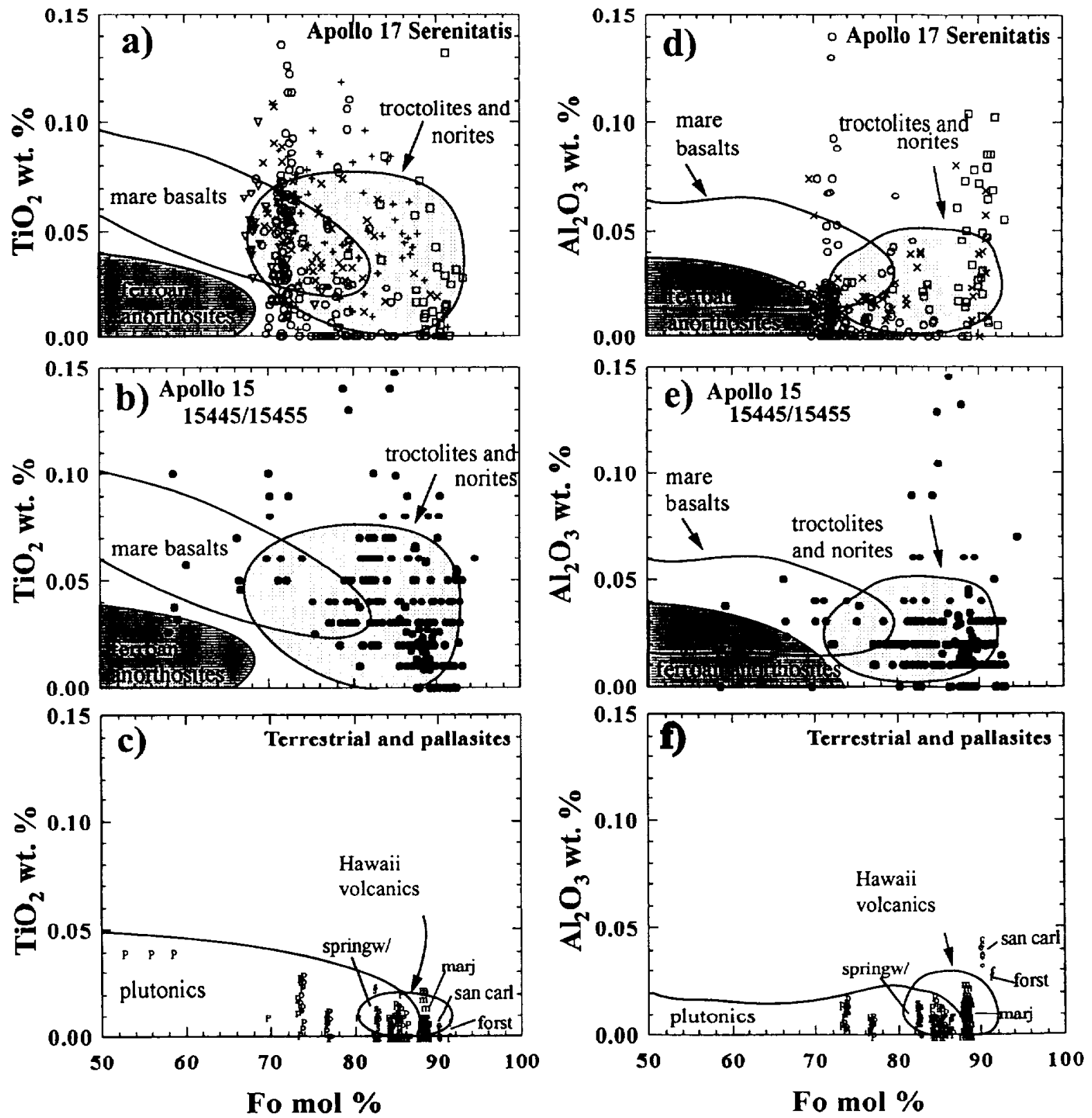

Fig. 9. $\mathrm{TiO}_{2}$ and $\mathrm{Al}_{2} \mathrm{O}_{3}$ vs. forsterite content for olivine fragments larger than $50 \mu \mathrm{m}$ in Serenitatis melt breccias and other olivine samples. Symbols and shading as in Fig. 8.

present. While it is not surprising that pyroxenes from rocks that have little pyroxene in them are not well-represented ( such as troctolites and anorthosites), their lack does demonstrate that such lithologies either are poorly represented in the target or were not interlayered with corresponding pyroxene-cumulates such as is common in terrestrial intrusions. Ferroan noritic anorthosites such as those found in 67215 and 67016 (McGee, 1988; Norman et al., 1995) are especially ruled out. It is apparent from the rarity of pyroxenes with intermediate- $\mathrm{Ca}$ contents that pyroxene-bearing volcanic rocks such as mare basalts or more-magnesian volcanic rocks contribute little or nothing to the population.

The low-Ca and high-Ca pyroxene fragments have minor element contents ( Fig. 11 ) partly similar to those in known Mg-suite gabbros and norites, but about half are conspicuously higher in $\mathrm{Ti}$ and $\mathrm{Al}$ and a little lower in $\mathrm{Cr}$ than pyroxenes from known pristine rocks (Fig. 11). The minor elements also rule out ferroan anorthosite as a significant contributor of pyroxene fragments. The abundance of highCa pyroxene fragments together with their tendency toward unusual compositions suggests the presence of poorly sampled gabbroic lithologies in the target. That gabbroic rocks may be more abundant in the lunar highlands than is apparent in the sample collection has also been suggested from remote sensing studies (Lucey and Hawke, 1988). The abundance of high-Ca pyroxene combined with the presence of rela- 

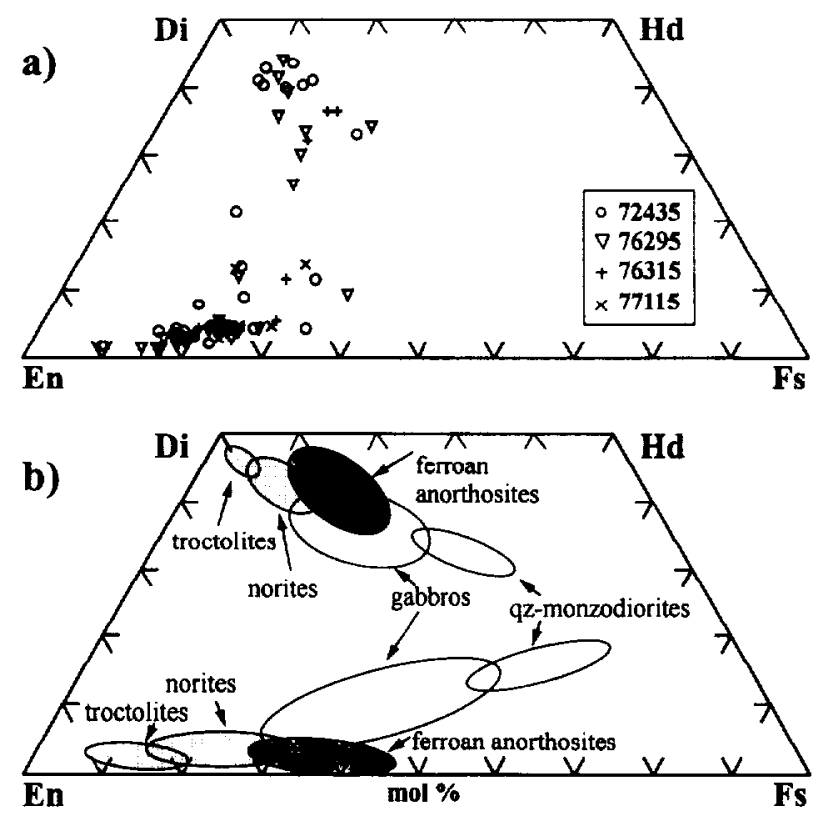

Fig. 10. Quadrilateral diagram for pyroxene compositions (a) fragments in Serenitatis melt breccias and (b) representative pyroxenes in comparative lunar igneous rocks. Ferroan anorthosites and Mg-suite norites and troctolites fields shaded as in Fig. 8.

tively Fe-rich olivine and pyroxene compositions suggest the presence of one or more evolved olivine-gabbronorite lithologies with overall characteristics similar to lherzolite 67667 (Warren and Wasson, 1978), but with distinct minor element abundances in the mafic phases.

While rapidly cooled crystalline impact melts can be ruled out as a source of pyroxene on the basis of both major and minor element data, as with olivine it is less easy to rule out a contribution from coarse-grained impact melts. Again, the lack of any lithic fragment of such crystalline melt in these rocks is circumstantial evidence that they do not contribute significantly to the pyroxene fragment population. Feldspathic granulites, particularly the coarser poikilitic (or poikiloblastic) varieties, cannot be discounted completely on compositional grounds and do contribute to the lithic fragment population.

\section{PLAGIOCLASE MINERAL FRAGMENTS IN SERENITATIS MELT BRECCIAS}

Our data for plagioclase mineral fragments and comparative lunar data are presented in Figs. 12 and 13, with representative analyses as Table 3 . We do not show comparative terrestrial data because the differences in the $\mathrm{Na}$ content and the dominance of $\mathrm{Fe}^{3+}$ in the terrestrial plagioclases (Longhi et al., 1976) render such comparisons difficult to interpret, if not meaningless. There are much fewer data for 15445 and 15455 plagioclases (Spudis et al., 1991) than for the Serenitatis melt breccia plagioclases and so we plot them on the same diagrams.

The compositions of plagioclase fragments vary widely for both major and minor element contents. The plagioclases have a much more continuous variation than do the olivine fragments, but there is no simple correlation between minor and major elements. There is a very obvious greater population density in the range $A b_{2-7}$ than at other compositions. We detect no significant differences in plagioclase populations among the different rocks; differences occur only in the sparsely populated sodic plagioclase fields. The data of Dymek et al. ( 1976) for plagioclase fragments in the Boulder 2 samples show a similar distribution.

The compositions for plagioclase fragments are generally consistent with those of $\mathrm{Mg}$-suite rocks, at least for those less sodic than $A b_{15}$. While many fragments in the denselypopulated area appear to be consistent with a ferroan anorthosite origin on the basis of $\mathrm{FeO}$ and $\mathrm{MgO}$ (Fig. 12) con-
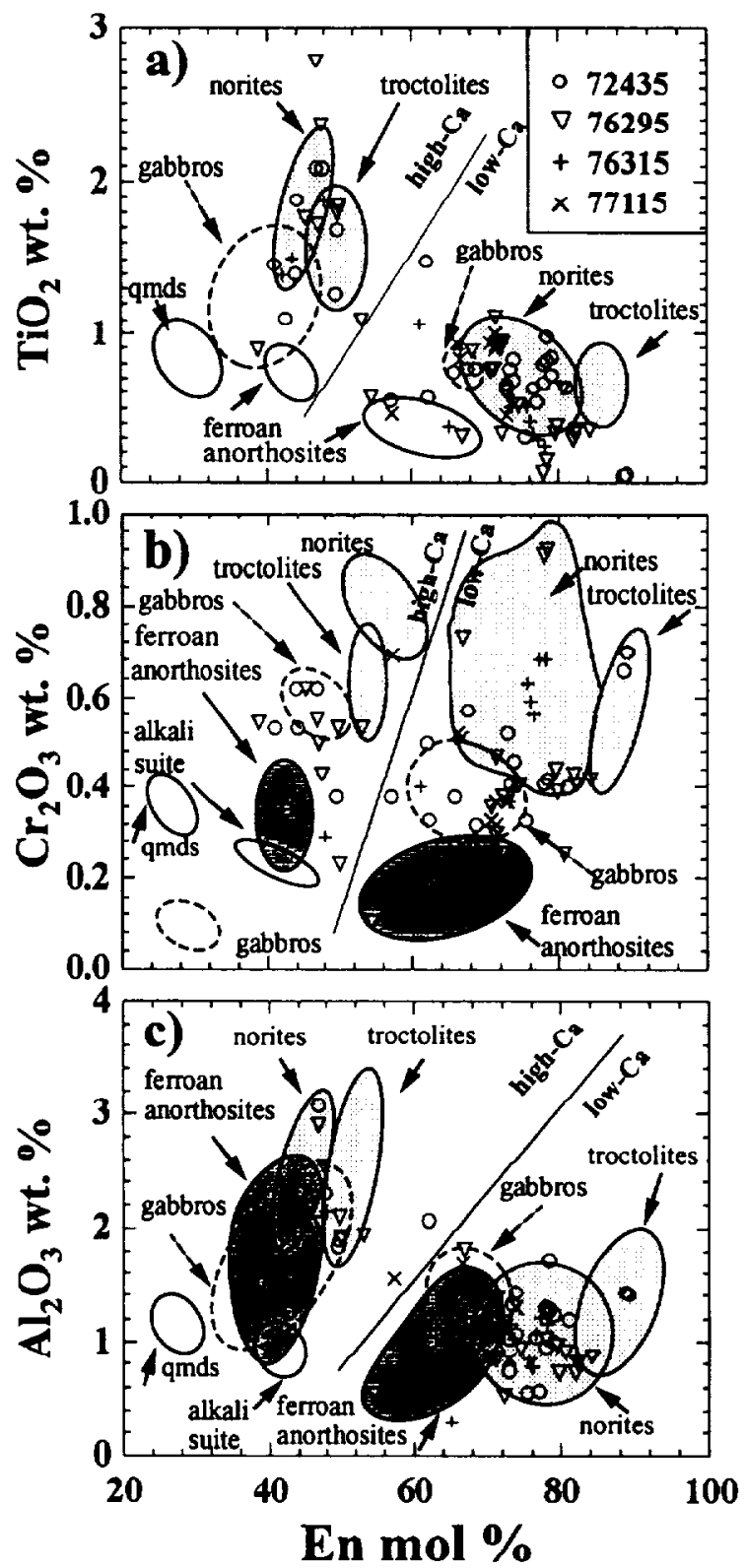

Fig. 11. Minor elements (a) $\mathrm{TiO}_{2}$ (b) $\mathrm{Cr}_{2} \mathrm{O}_{3}$ and (c) $\mathrm{Al}_{2} \mathrm{O}_{3}$ vs. enstatite content for pyroxene fragments in Serenitatis melt breccias, with fields for comparative lunar igneous rocks. qmds = quartz monzodiorites. Ferroan anorthosites and $\mathrm{Mg}$-suite norites and troctolites fields shaded as in Fig. 8. 

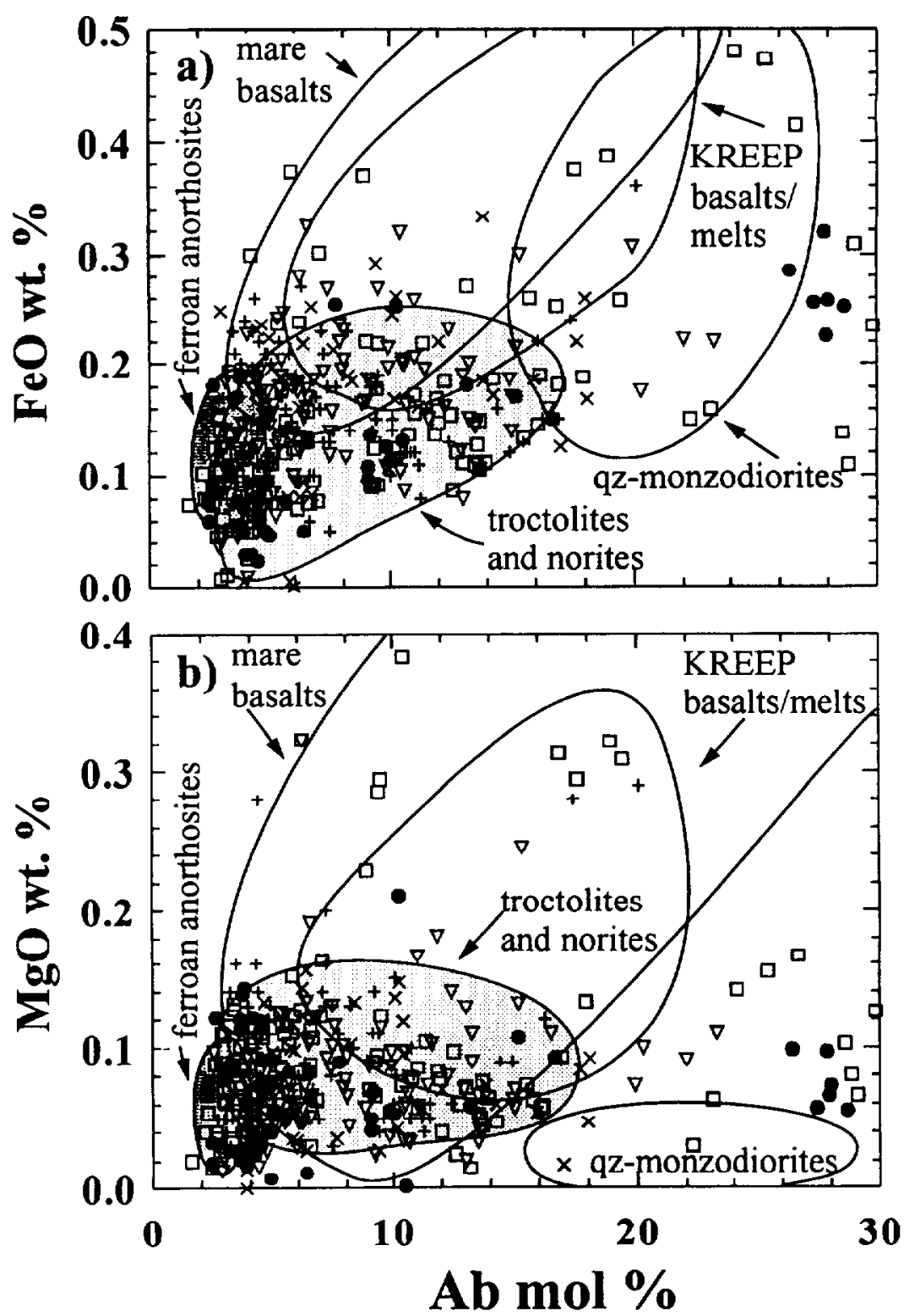

Fig. 12. (a) $\mathrm{FeO}$ and (b) $\mathrm{MgO}$ vs. albite content for plagioclase fragments in Serenitatis melt breccias, with fields for comparative lunar igneous rocks. Ferroan anorthosites and $\mathrm{Mg}$-suite norites and troctolites fields shaded as in Fig. 8.

tents, the $\mathrm{K}_{2} \mathrm{O}$ contents are generally higher and more consistent with an Mg-suite origin (Fig. 13). However, the range extends outside that of such rocks so far analyzed. A very few have low enough $\mathrm{K}_{2} \mathrm{O}$ contents that a ferroan anorthosite origin appears more likely, though not absolutely required. (The affinity of these grains could be resolved with analysis of other trace elements using different methods). Similarly, mare basalt plagioclases contain too much Fe to be appropriate sources for all but a few of the plagioclase fragments in the Serenitatis melt breccias. Typical KREEP volcanic plagioclases also have fields for $\mathrm{FeO}$ and $\mathrm{MgO}$ that are only sparsely populated by the Serenitatis plagioclase fragments. The minor element fields for plagioclase in alkali anorthosites are not well known. Crystalline impact melts have pla- gioclases which fall in the wide general range of compositions as Mg-suite, KREEP, and mare basalts for FeO, but reliable analyses for $\mathrm{MgO}$ and $\mathrm{K}_{2} \mathrm{O}$ are sparse and reliable comparisons cannot be made. Similarly, data on minor elements for feldspathic granulites are sparse, and at least some of which are coarse-grained enough to be, in principle, contributors to the plagioclase population of the Serenitatis melt breccias. We cannot rule them out as significant contributors to the plagioclase fragment populations.

Many of the sodic plagioclases $\left(A b_{>15}\right)$ fall in the major element field of those in quartz monzodiorites, but the latter have extremely low $\mathrm{MgO}$ contents well outside the range of the Serenitatis fragments. Thus, the plagioclase data are in agreement with the pyroxene data in that rocks like known 

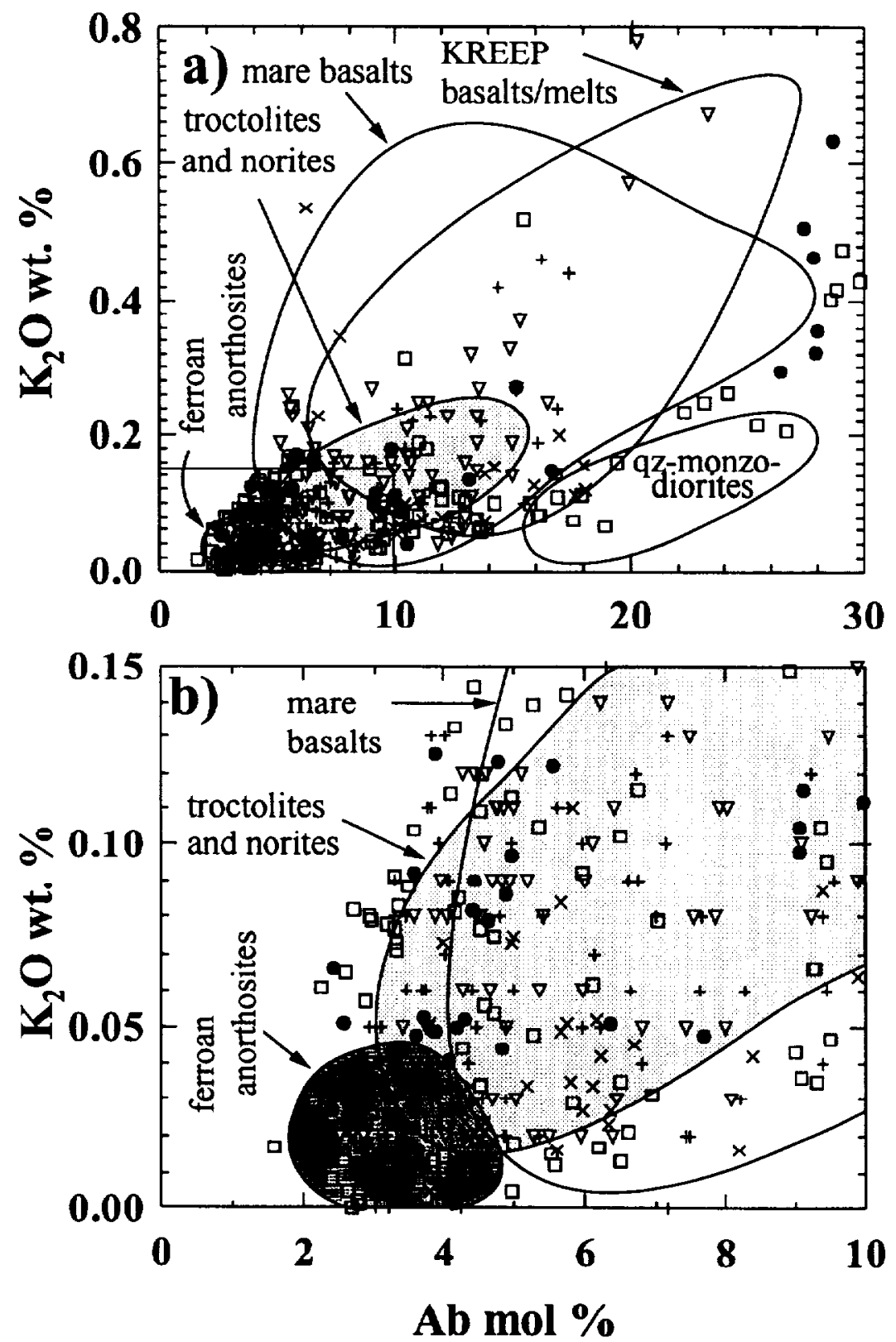

Fig. 13. (a) $\mathrm{K}_{2} \mathrm{O}$ vs. albite content for plagioclase fragments in Serenitatis melt breccias, with fields for comparative lunar igneous rocks. Ferroan anorthosites and $\mathrm{Mg}$-suite norites and troctolites fields shaded as in Fig. 8. (b) expanded view of the rectangle marked in the lower left corner of (a).

quartz monzodiorites are not significant constituents of these breccias. It would appear most likely that these sodic plagioclases come from rocks that are an extension of the $\mathrm{Mg}$ suite range into other more evolved rocks, more like sodic ferrogabbros or 67667 or possibly alkali anorthosites, and not like known KREEP or quartz monzodioritic rocks.

\section{COMPARISON WITH FRAGMENTS IN 15445 and 15455 (IMBRIUM?) MELT BRECCIAS}

Spudis et al. (1991) concluded that the sources of olivine fragments in the 15445 and 15455 low-K Fra Mauro melt breccias were dominated by a variety of $\mathrm{Mg}$-suite rocks, but included rocks outside the known suite. As for the Serenitatis melt breccias, the olivine fragments in the possible Imbrium melt breccias represent mainly plutonic and hypabyssal lithologies, but some of those with highest $\mathrm{CaO}$ contents might represent volcanic rocks. Both ferroan anorthosites and mare basalts were inferred to be absent or rare. However, in detail the populations of the Serenitatis melt breccias differ from those of their Apollo 15 counterparts, including a wider range of major element compositions (Figs. 8, 9, and Ryder and Bower, 1977; Reid et al., 1977).

The olivine population in the Apollo 15 breccias is shifted heavily towards magnesian olivines, reflecting a greater preponderance of more magnesian rocks in the pick-up zone. 
Some of these Apollo 15 magnesian olivines are distinct from those in the Serenitatis melt breccias; many have very low $\mathrm{CaO}$ contents consistent with more spinel troctolite such as exists as lithic fragments in 15445 but not in the Serenitatis melt breccias. Few of the Apollo 15 olivines are like the distinct high Fo, high $\mathrm{CaO}-\mathrm{Cr}_{2} \mathrm{O}_{3}-\mathrm{Al}_{2} \mathrm{O}_{3}$ olivines that characterize 76035, though some have high $\mathrm{Cr}_{2} \mathrm{O}_{3}$, and others have high $\mathrm{Al}_{2} \mathrm{O}_{3}$ contents. Some of the olivines in the Apollo 15 breccias are also rather more Fe-rich than any in the Serenitatis breccias. Although this could reflect less resorption in the even finer-grained Apollo 15 melts, these might represent lithic types not even present in the Serenitatis pick-up zone. They are sparse and might represent Fe-rich relatives or extensions of the $\mathrm{Mg}$-suite rocks, or Fe-rich rocks of completely different origin; they are not consistent with ferroan anorthosite origins. While some could reflect mare basalt origins, this seems unlikely given the lack of pyroxene fragments from mare basalts (below).

Given the differences among the Serenitatis samples, some caution is necessary in inferring that the Apollo 17Apollo 15 differences are of fundamental significance. However, because both of the Apollo 15 melt breccia samples are also more magnesian in bulk chemistry than the Apollo 17 Serenitatis melt breccias (about $16 \mathrm{wt} \% \mathrm{MgO}$ in contrast with about $13 \mathrm{wt} \% \mathrm{MgO}$ ) then the fragment population difference is probably meaningful. The fragment population of the Apollo 15 melt breccias is probably not in itself adequate to produce the bulk chemical difference from the Apollo 17 Serenitatis melt breccias (which also have higher abundances of incompatible elements). Thus it is likely that both the melt sources (i.e., ground zero) and the pick-up or excavated zones were compositionally distinct, with the Apollo 15 melt breccias being derived from a target that was generally more magnesian than that of the Serenitatis melt breccias.

We have very little data for pyroxene fragments in 15445 and 15455 (Spudis et al., 1991), and much of that appears to be biased towards the contribution of mineral debris derived from a single large anorthositic norite fragment in 15455. Thus we have little basis for comparison, except to repeat that these Apollo 15 samples also appear to have pyroxenes more compatible with an origin in $\mathrm{Mg}$-suite norites and gabbros, whereas pyroxenes from ferroan anorthosites, mare basalts, KREEP basalts, or evolved lithologies such as quartz monzodiorites are absent.

Few data are available for minor elements in plagioclases in 15445 and 15455 (Spudis et al., 1991). The overall distribution is similar to that for the Apollo 17 Serenitatis melt breccias, including the higher population density in the range $\mathrm{Ab}_{2-7}$ (Figs. 12, 13). Thus both breccia suites are consistent with generally similar source rocks, with most plagioclases from $\mathrm{Mg}$-suite rocks, and evolved sodic, gabbroic varieties of them (not necessarily related to known varieties). There is a lack or extreme rarity of both ferroan anorthosite and mare basalt plagioclases in both suites. $A$ cluster at $\mathrm{Ab}_{27-28}$, which are analyses of a single $400 \mu \mathrm{m}$ diameter zoned grain in the Apollo 15 samples, is not derived from quartz monzodjorite, as this plagioclase grain contains substantially more $\mathrm{MgO}$ and $\mathrm{K}_{2} \mathrm{O}$ than quartz monzodiorite plagioclases (Figs $12,13)$. It is more like that of plagioclase from sodic ferro- gabbro and is similar to that of the few most sodic plagioclases in the Serenitatis melt breccias.

\section{IGNEOUS LITHIC FRAGMENTS IN THE SERENITATIS MELT BRECCIAS}

All of the pristine igneous rocks that occur as lithic fragments within the Serenitatis melt breccias are members of the diverse and nonconsanguinous $\mathrm{Mg}$-suite. Some were large enough to be observed and sampled individually, such as the dunite in the boulder represented by melt breccia 72435 (Dymek et al., 1975) and the norite in the Station 7 boulder (Chao et al., 1976). Some of the individual plutonic rock samples from Apollo 17 are similar to fragments in the boulders and may have once been in the Serenitatis melt (e.g., troctolites 76535 and 76536 , which were collected adjacent to the Station 6 boulders). Most of the large igneous fragments are norites and troctolites; the dunite 72415 as a handsample is unique in the lunar collection. Spinel-bearing troctolites, gabbros, granites, and basalts are present in the melt breccias, but are much less common than norites and troctolites, and they occur only as small fragments observed in handsamples or thin sections (e.g., Dymek et al., 1976; Warner et al., 1976).

No sample of ferroan anorthosite has been observed in the Serenitatis melt breccias. Samples described as anorthositic (e.g., Dymek et al., 1976) are feldspathic granulites, which are metamorphosed breccias (Cushing et al., 1997). Our observations of many thin sections as well as our interpretation of published reports show that feldspathic granulites are actually the most common lithic fragments in the Serenitatis melt breccias, at least in number; at least some of them are from large fragments observed and individually sampled on the Moon (e.g., 76235). Most of them are fine-grained (less than $100 \mu \mathrm{m}$ ), and at least a few are poikilitic.

The mineral fragments in the Serenitatis melt breccias come from a population of rock types that is similar to but more diverse than that represented by the lithic fragments. Because of their fine grain sizes, it is unlikely that the granulites contribute significantly to the population of mafic mineral fragments, except perhaps in the smallest fragment sizes. They might be a more significant contributor to the plagioclase fragment population. By the very nature of our study we cannot directly observe the relationships among the three different mineral phases we analyzed as fragments, e.g., we cannot observe whether a particular olivine is from a dunite, a troctolite, or an olivine-norite, nor what pyroxene or plagioclase composition it might have coexisted with. Such relationships might be deduced with a study of the minor elements in mineral phases in the small lithic fragments; published descriptions and data are inadequate. Nonetheless, we suppose that most of the mafic mineral fragments coexisted in their source rocks with plagioclases, because within these melt breccias bona fide dunites are rare among even small lithic fragments, and pyroxenites are absent.

\section{IMPLICATIONS FOR CRUSTAL COMPOSITION AND THE DYNAMICS OF BASIN FORMATION}

\subsection{Components in the Serenitatis Melt}

The bulk rock major and minor element compositions of the Serenitatis melt breccias are approximated by samples 


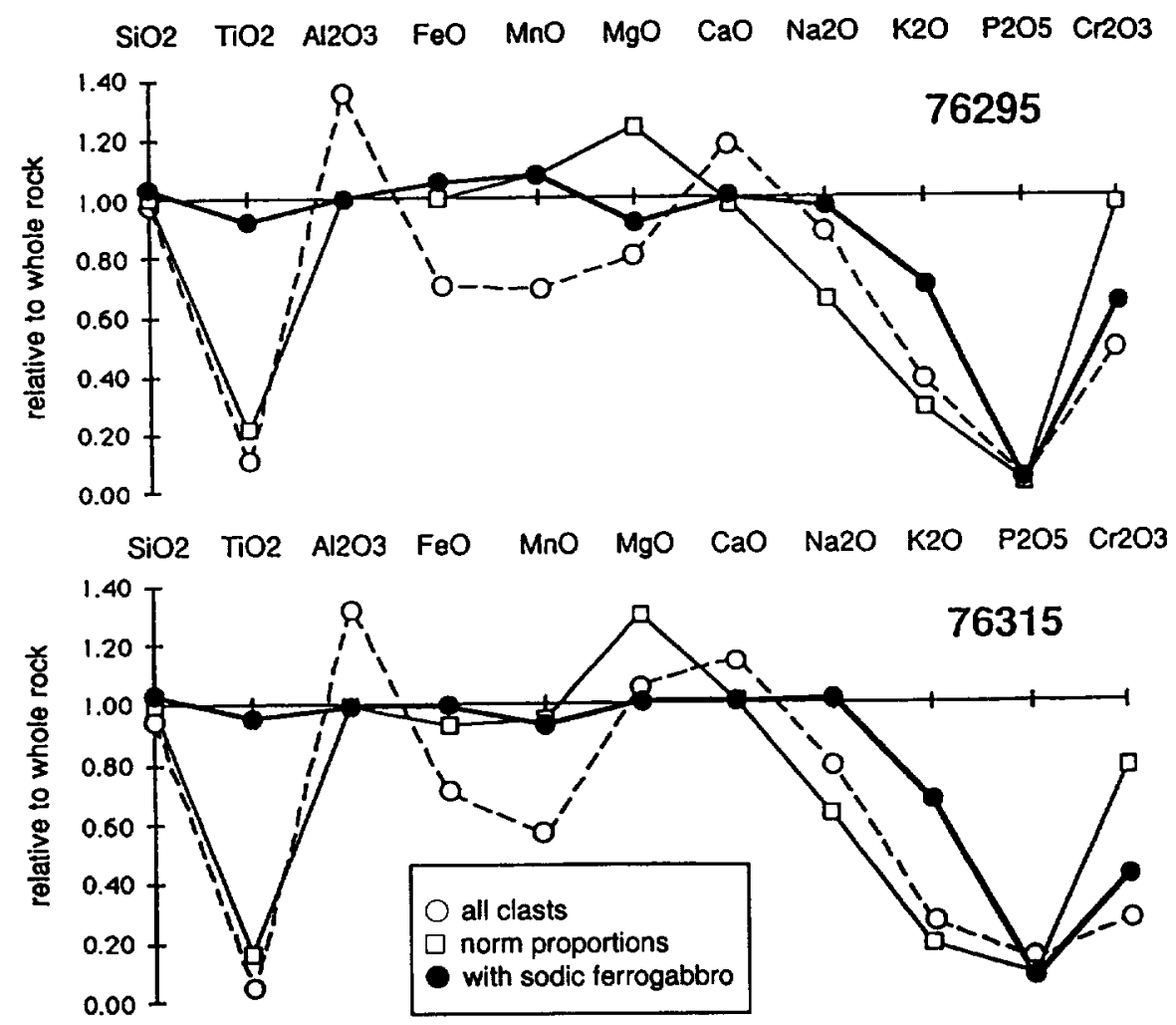

Fig. 14. Comparison of three mixing models of clast compositions with major element rock analyses for 76295 and 76315 (see text for explanation).

from other sites. This particular composition has been found only as meteorite-contaminated, fragment-bearing, impact melt samples, i.e., as mixtures, not as igneous rocks. The term, low-K Fra Mauro basalt, was first used for a cluster of compositions of impact glass particles from the Apollo 15 landing site (Reid et al., 1972) that are similar in composition to basaltic impact glasses and breccias found in (or on) the Fra Mauro Formation at the Apollo 14 landings site, but with less $\mathrm{K}\left(<0.2 \mathrm{wt} \% \mathrm{~K}_{2} \mathrm{O}\right)$ and lower abundances of other incompatible elements. The name of low-K Fra Mauro was gradually extended in use to a slightly wider range of compositions, and many melt breccias containing 17-20 wt $\% \mathrm{Al}_{2} \mathrm{O}_{3}$ at the Apollo 15, 16, and 17 sites, but with $\mathrm{K}_{2} \mathrm{O}$ up to $0.4 \mathrm{wt} \%$, were included in this category (e.g., Vaniman and Papike, 1980). While a broad group, it is made up of subgroups with analytically distinguishable compositions (e.g., Ryder and Spudis, 1987; Korotev, 1994), one of which is the Apollo 17 Serenitatis melt breccia composition.

The bulk chemical composition of the low-K Fra Mauro melts cannot be derived from a mixture of the lithic fragments that the samples contain (Ryder, 1979). Furthermore, when numerically modeled as a mixture of any known lunar igneous rocks, there is always one or more cryptic (missing) components rich in highly incompatible elements such as the rare earth and also transition metals (e.g., Ti, Sc). This is in marked contrast with the impact melt sheets in terrestrial craters, where the major and trace element compositions of most impact melt rocks can be very satisfactorily modeled as mixtures of the surrounding country rocks (e.g., Grieve,
1975; Grieve and Floran, 1978). One objective of the present study was to search for mineral fragments that could be derived from the cryptic components. The positive correlation between rare earth elements and $\mathrm{Ti}$ contents within the Serenitatis melts (Stockstill and Ryder, 1995) suggests one (or similar, if more than one) component rich in both rare earth and transition elements. Thus, the cryptic component might be characterized by olivines and pyroxenes with higher $\mathrm{Ti}$ and $\mathrm{Cr}$ contents, and plagioclases with higher $\mathrm{Na}$ contents, than their counterparts in known pristine highland rocks.

We illustrate the discrepancy between fragments and melt compositions in Fig. 14. We modelled the composition of melt breccias 76295 and 76315 in two ways. First, we simply averaged all our mineral analyses from both of these breccias. This is a reasonable approximation of the bulk fragment population, because we tried to analyze nearly every grain in those two rocks, and the grain size of these fragments is fairly uniform. The data show that the fragments are enriched in plagioclase relative to the whole rock, the fragments have an overall higher $\mathrm{mg}^{*}[100 \times \mathrm{Mg} /(\mathrm{Mg} / \mathrm{Fe})$ atomic $]$ than the whole rock, and there is a strong deficiency in $\mathrm{Ti}$, the alkalies, and $\mathbf{P}$ contents (and, one can reasonably infer, also a deficiency in the rare earth and other incompatible elements) in the fragments. Second, we mixed the fragments in proportions corresponding to the whole rock norm. As expected, this improves the fit somewhat (Fig. 14), but the fragments still have higher $\mathrm{mg}^{*}$ and a deficiency in Ti, alkalies, and $\mathbf{P}$ contents. While oxide and phosphate minerals in 
the target can be expected to supply some of these elements to the impact melts, we have not recognized indisputable fragments of such phases in these rocks.

Our microprobe data (Figs. 6-13) indicate that some mineral fragments are derived from gabbroic rocks. The few gabbros among pristine rocks are characterized by sodic plagioclase, high-Ca pyroxenes with a range in $\mathrm{TiO}_{2}, \mathrm{Cr}_{2} \mathrm{O}_{3}$, and $\mathrm{Al}_{2} \mathrm{O}_{3}$ contents, and relatively $\mathrm{FeO}$-rich olivines. They are at least generally suitable as candidates for contributing to the cryptic component. Many of the pyroxene fragments in the Serenitatis melts are from similar gabbros, and the high-Ca pyroxenes tend to be at the high-Ti and high-Al end of the range found in these gabbros. In fact, several pyroxene fragments contain more $\mathrm{TiO}_{2}$ and $\mathrm{Al}_{2} \mathrm{O}_{3}$ than reported for pyroxenes in pristine gabbros. In addition, some low-Ca pyroxene fragments with compositions like those in iron-rich norites (about $\mathrm{En}_{70}$ ) contain significantly more $\mathrm{TiO}_{2}$ than low-Ca pyroxenes in pristine norites (Fig. 11), although $\mathrm{Cr}_{2} \mathrm{O}_{3}$ does not appear to be similarly enriched. We suggest that sodic gabbronorites may be one of the components present, mainly in cryptic form, in the poikilitic melt breccias.

To test this suggestion more quantitatively, we have examined the possibility that sodic ferrogabbro such as that in breccia 67915 could represent a significant component in the melt phase of the Serenitatis breccias. We chose this rock because its composition is reasonably well established and it contains the most $\mathrm{TiO}_{2}$ of all the gabbronorites (Marti et al., 1983). Adding 25\% sodic ferrogabbro to the mineral fragments in 76015 and 76315 produces a good fit for $\mathrm{Ti}$, $\mathrm{mg}^{*}$, and $\mathrm{Na}$ in the bulk breccia, but $\mathrm{K}, \mathrm{P}$, and presumably other highly incompatible trace elements such as rare-earth elements remain too low. Addition of only about $0.5 \%$ of a whitlockite or apatite would provide the necessary $\mathbf{P}$ and probably rare earth elements, but not $\mathrm{K}$.

Wasson et al. ( 1977 ) tried to derive the composition of the missing component and produced a hypothetical component, abbreviated SCCRV (for Sc, Cr, and V). The composition of SCCRV is similar to gabbro-norite (or feldspathic lherzolite) 67667 (Warren and Wasson, 1979). However, 67667 itself is incapable of providing the incompatible elements that characterize the Low-K Fra Mauro composition. Other gabbros, such as that in 73155 (Ryder, 1992b and unpubl. chemical data) may be more promising, but the chemical data base for the small, sparse gabbros that exist in the Serenitatis melt breccias is poor. We conclude that a component with a composition similar to the sodic ferrogabbro is an important ingredient in the Serenitatis melts, providing the necessary transition elements. Another component $(s)$ is required to provide the $P, K$, and rare earth elements. As noted in a previous section, gabbronorites may be much more abundant on the Moon than is apparent from the lunar sample collection (Lucey and Hawke, 1988). Similarly, types of sodic ferrogabbro were required among the chemical components of impact melt from the Apollo 16 landing site (Lindstrom and Salpas, 1983; Stöffler et al., 1985), but solutions are not particularly satisfactory, suggesting more complex mixtures or a different ferrogabbroic lithology.

A vital yet unanswered question is why the low-K Fra Mauro component, or components, are essentially always cryptic, represented at best by sparse small mineral fragments and even sparser lithic fragments.

\subsection{Implications of Very Magnesian Olivines ( $\mathbf{F O}_{\mathbf{8 7 - 9 4}}$ )}

A prominent group of magnesian olivines $\left(\mathrm{Fo}_{87-94}\right)$ is present in both the Serenitatis and Imbrium melts. The rarity of similarly magnesian pyroxenes suggest that these olivines are derived from either dunites or troctolites, or their volcanic equivalents, rather than from harzburgites or olivinenorites. Plagioclase fragments with compositions most consistent with derivation from troctolites $\left(A n_{>94}\right)$ are common in the melt breccias (Figs. 12,13), so it is reasonable to assume that at least many of these olivines are also from troctolites, rather than from dunites. We cannot unambiguously rule out the possibility that the magnesian olivines in the Serentatis melts are either dunites or fragments of the lunar mantle, but we assume in the following discussion that the magnesian olivines come from troctolites or their volcanic equivalents. This is especially reasonable for breccias which have high olivine/pyroxene ratios (e.g., 76315; Norman et al., 1992) and also carry abundant fragments of plagioclase.

Hess (1994) has discussed the significance of the high $\mathrm{mg}$ * of lunar troctolites, which ranges from 86 to 92 , and pointed out the difficulties in current models of their petrogenesis. Our data shows that the $\mathrm{mg}$ * range extends up to at least 94 , exacerbating the petrogenetic problems outlined by Hess (1994). One basic problem in understanding the petrogenesis of such troctolites is that the rocks formed from magmas saturated with plagioclase and olivine, yet highly magnesian magmas, tend to precipitate olivine alone. To reach plagioclase saturation, the magma must fractionate olivine, which decreases the $\mathrm{mg}$ * of the magma. To reach plagioclase saturation with the $\mathrm{mg}$ * still in the range $90-$ 94 , the source rock (primitive lunar mantle or magma ocean cumulate) must have very high $\mathrm{mg}^{*}$, probably $>94$. Assimilation of the ferroan anorthosite crust has been proposed to raise the $\mathrm{Al}_{2} \mathrm{O}_{3}$ of the magmas to plagioclase saturation (e.g., Warren, 1986), but Hess (1994) argues compellingly that this is either a very inefficient process (if it involved dissolution of ferroan anorthositic wallrock) or causes the $\mathrm{mg}$ * of the magma to decrease substantially (if the assimilation involved partial melting of the wallrock). Thus, it appears that at least some portion of the lunar interior has an $\mathrm{mg}^{*}$ * greater than the conventional bulk moon value of $80-84$ (Jones and Delano, 1989; O'Neill, 1991), as argued by Warren (1986). This might be taken as consistent with a cumulate model for the lunar magma ocean, and suggesting a magma ocean that was a near-total melt.

There is good evidence that the mare basalt source regions, corresponding to the lunar mantle down to about $500 \mathrm{~km}$, have $\mathrm{mg} *$ of 75-84 (e.g., Mueller et al., 1988). Nevertheless, the lower mantle could have had higher $\mathrm{mg} *$, and it is possible that the magnesian ultramafic parent magmas for troctolites formed by partial melting of the primitive deep interior (Hess, 1994), perhaps caused by displacement and pressure-release melting of the primitive interior by sinking of dense late-stage cumulates from the magma ocean (Hess and Parmentier, 1995). If so, it implies a primoridal compositional zonation in the Moon, with a deep interior more magnesian than the shallower regions that melted to form the magma ocean. Such a zonation might have been caused by fractional condensation and heterogeneous accretion from 
a hot debris cloud surrounding the Earth, if the Moon formed as the result of a giant impact. The first condensates or refractory residues remaining after the impact would be greatly enriched in $\mathrm{MgO}$, as we know from studies of the thermodynamics of condensation in the solar nebula (e.g., Wood and Hashimoto, 1993) and from evaporation experiments (Hashimoto et al., 1979); subsequent condensates would be richer in $\mathrm{FeO}$. Compositional variations caused by partial volatilization (Raleigh fractionation) during the heating event can be ruled out, however, by the uniformity in magnesium and potassium isotopic compositions in lunar and terrrestrial materials (Esat and Taylor, 1992; Humayun and Clayton, 1995). An alternative, discussed by Hess (1994) is reduction of $\mathrm{FeO}$ in troctolitic magmas to metallic iron, thus raising $\mathrm{mg}^{*}$. This might also explain the low $\mathrm{Ni}$ contents in the olivines of troctolites (Ryder, 1983). This can be tested by analyzing $\mathrm{Ni}$ in the olivines with high $\mathrm{mg}$ *, beyond the scope of the present study.

If the olivines with high $\mathrm{mg}^{*}$ in the Serentatis melts are samples of the lunar mantle or are from komatiitic lavas (not saturated with plagioclase), the arguments of Hess (1994) still apply to pristine troctolites, which have mg* up to 92 . However, the presence of very magnesian olivines in the mantle does not by itself require that the Moon have a high $\mathrm{mg} *$. Olivines with $\mathrm{mg}^{*}$ of 92-94 would crystallize from magmas with mg* of $78-84$ at $<20 \mathrm{~kb}$ (see Fig. 2 of Hess, 1994 ), consistent with crystallization in a magma ocean formed by total melting of a moon with $\mathrm{mg} *$ of about $80-$ 84 (e.g., Taylor, 1982; Jones and Delano, 1989). Thus, if the very magnesian olivines in the Serenitatis melt breccias are derived from the mantle, they represent the first cumulates from the lunar magma ocean. Such rocks have low densities and would rise diapirically to form the upper mantle of the Moon (e.g., Hess and Parmentier, 1995). However, this explanation does not account for the association of extremely magnesian olivines with plagioclase in the lunar troctolites. Nor does it immediately account for those high$\mathrm{Mg}$ olivines with high $\mathrm{CaO}$, which quenched from a high temperature.

\subsection{Crustal Stratigraphy in the Serenitatis and Imbrium Regions}

The multiringed basins on the Moon provide access to the subsurface levels of the crust, allowing us, in principle, to determine the stratigraphy of the crust. The melt formed by the explosion of hypervelocity impact provides information about the deeper levels of the crust below the target point, which is otherwise commonly inaccessible; what might be left of it is buried beneath ejecta fallback, ejecta from subsequent impacts, and flooding by mare lavas at much later times. The bulk chemical composition of the melt breccias and the lithic and mineral fragments entrained in them provide information about rocks at the target and in near-target areas.

Spudis (1993) synthesized the current understanding and debate on the geology and the processes of formation of multi-ringed basins. Knowledge about the production of impact melts in basins is based on observational, experimental, and theoretical considerations (e.g., Simonds et al., 1978; Melosh, 1989; Cintala and Grieve, 1994; O'Keefe and Ah- rens, 1994). The melt is created by shock heating at and below the impact site, to a depth of perhaps tens of kilometers (Fig. 2). It is initially superheated and thus of low viscosity, and the turbulent mixing creates a homogeneous melt. During the excavation phase the melt moves out, and a planar sheet of it lines the transient cavity. Some melt spills out and some is ejected along ballistic trajectories. As the crater grows and the melt moves outwards, the melt enounters and entrains cooler, lesser- or unshocked fragmental debris, ultimately from shallower levels. In a large basinforming event, horizontal movement of the melt is actually upwards as well, because of the curvature of the Moon. The fragments in the melt do not represent those rocks from the immediate point at which the melt formed. Fragments also react with the melt and can be resorbed by it and influence its cooling (Simonds, 1975; Thornber and Huebner 1980; Sanford and Huebner 1980). Those fragments that are immersed in the melt at its most superheated are probably closest to ground zero and would be the most shock-heated fragments, prone to the greatest degree of resorption or reaction with the melt. Those fragments picked up later are less shock-heated and are less affected by the by-then cooler melt.

Cratering dyamics theory suggests that the Serenitatis melt was generated entirely within the lunar crust (Fig. 2). Warren et al. (1996) calculated (based on physical models) the amount of mantle material in impact melts ejected during the formation of lunar basins. For basins the size of Serenitatis, their calculations predict that virtually no mantle material should be incorporated, consistent with our observations that essentially all fragments are derived from crustal rocks. The few that could conceivably be from the mantle (the olivine fragments with Fo of 90-94) are not abundant nor likely to be from the mantle (see above). In addition, the bulk breccia compositions are consistent with derivation entirely from the crust.

It has been argued previously (Ryder and Wood, 1977; Spudis, 1984; Spudis and Davis, 1986) that low-K Fra Mauro impact melts represent the composition of the lower crust, and that the entrained fragments were derived from crustal material stratigraphically higher than the zone of melting during basin formation. The main arguments for this view are the likely association of the Apollo 15 and 17 lowK Fra Mauro impact melt breccias with basin ejecta (Ryder and Wood, 1977), and the direct correlation in basin ejecta of noritic components with basin size (Spudis and Davis, 1986). Recent results from the Clementine mission are consistent with this interpretation (Lucey et al., 1995; Spudis et al., 1996). The floor of South Pole-Aitken basin, the largest lunar basin ( $2500 \mathrm{~km}$ in diameter), might be a roughly equal mixture of low-K Fra Mauro basalt and mantle rock. According to physical models, the melt retained inside a basin is produced from the greatest depths (e.g., Cintala and Grieve, 1994), consistent with the South Pole-Aitken floor being a mixture of the lower crust of low-K Fra Mauro composition and the upper mantle (Lucey et al., 1996), or even without mantle (Lucey et al., 1995).

The Apollo 17 Serenitatis melt breccias, like the Apollo 15 black and white breccias we studied previously (Spudis et al., 1991), contain only about $18 \mathrm{wt} \% \mathrm{Al}_{2} \mathrm{O}_{3}$. That is much lower than the average surface of the lunar highlands 
crust (Spudis and Davis, 1986; Lucey et al., 1995), and these breccias are essentially an aluminous basalt in chemical composition. The composition of those massif regoliths least-contaminated with mare basalt (e.g., regolith at Station 2 with 21 wt $\% \mathrm{Al}_{2} \mathrm{O}_{3}$, and regolith breccia 73131 with 22.6 wt $\% \mathrm{Al}_{2} \mathrm{O}_{3}$; Korotev and Kremser, 1992; Rhodes et al., 1974 ) suggest that the massifs are rather more aluminous in bulk composition than are the Serenitatis melt breccias. The massifs probably contain substantially more plagioclase in the form of feldspathic granulites, consistent with the presence of granulites in the soils (e.g., Ryder, 1981; Jolliff et al., 1996), as individual rock fragments (Warner et al., 1977), and as fragments within the Serenitatis melt breccias (Dymek et al., 1976; Spudis and Ryder, 1981). The Apollo 17 aphanitic melt breccias (e.g., Boulder 1, Station 2) are also somewhat more aluminous $\left(20-21 \% \mathrm{Al}_{2} \mathrm{O}_{3}\right)$ and contain abundant feldspathic granulite fragment material (Ryder et al., 1975). In addition, our unpublished results using data from the Clementine and Galileo missions indicate that the massifs surrounding the Apollo 17 site contain 8-10 wt\% $\mathrm{FeO}$, which corresponds to $20-22 \mathrm{wt} \% \mathrm{Al}_{2} \mathrm{O}_{3}$ (see Fig. 8.3 in Heiken et al., 1991). In fact, it is over $200 \mathrm{~km}$ from the Apollo17 site before the $\mathrm{FeO}$ drops below $6 \mathrm{wt} \%$, still substantially greater than the farside highlands. The compositional difference between the Serenitatis melt breccias and the Taurus-Littrow massifs shows that the latter are not excavated from the melt zone: they are either uplifted blocks of pre-Serenitatis materials, or they are derived from excavated material that was stratigraphically above the melt zone, or closer to the Taurus-Littrow region than is the basin center, or both. In any case, the aluminous composition of the massifs demonstrates a heterogeneity of the lunar crust around the Serenitatis basin. Quite possibly the feldspathic granulites within the Serenitatis melt breccias were picked up in this stratigraphically higher zone, closer to the Apollo 17 site, while the Mg-suite igneous rocks and the mineral fragments such as we analyzed were derived from stratigraphically deeper materials that were originally much closer to, and compositionally more similar to, the melt zone.

According to Warren et al. (1996), ejecta from the Imbrium basin similarly would not contain significant amounts of material derived from the mantle. This is consistent with our previous inference (Spudis et al., 1991) that fragments in the Apollo 15 black and white rocks (strong candidates for Imbrium impact melt) are all derived from the lunar crust. Assuming that the Apollo 17 melt breccias described here are ejecta from the Serenitatis event and that the Apollo 15 melt breccias described previously are ejecta from the Imbrium event, our data are consistent with current physical models depicting the provenance of materials ejected from lunar basins.

The compositions of the Serenitatis melts, the nature of the fragments in the breccias, and regional compositions determined by remote sensing demonstrate that the lunar crust in the vicinity of the Serenitatis basin is, or was, vertically heterogeneous (Fig. 15). Rocks were formed at a variety of depths, or at least at a variety of cooling rates, and many different parent magmas are required to account for them. While surface flows are either absent or rare (with the possible exception of a komatiite-like rock type), both $\mathrm{Ca}$ in olivine and pyroxene exsolution suggest that very shallow, or hypabyssal, intrusions appeared in the crust of this region (Ryder, 1984a, 1992a; McCallum and O'Brien, 1995, 1996; O'Brien and McCallum, 1996). The deepest crust sampled by the Serenitatis melt breccias, not necessarily the deepest crust, is aluminous basalt in composition and apparently a mixture of lithologies, including KREEP and gabbroic rocks like the sodic ferrogabbro. These are overlain by $\mathrm{Mg}$-suite rocks, some of which are very slowly cooled plutonics, whereas others are rather shallower according to inferred cooling rates. Alternatively the more-rapidly cooled varieties might be younger and intruded into older, colder crust rather than shallower. It is clear that the lunar crust in this region that includes the Serenitatis target area, probably extending to the Imbrium target area, was built up by complex and serial magmatism, not by a single crust-forming event.

Granulites, very common as lithic fragments but apparently less abundant as a source of mineral fragments, are more abundant near the surface. The thermal histories of some granulites are consistent with their formation in the uppermost kilometer of the Moon (Cushing et al., 1997). Conspicuous by their absence in the Serenitatis melt are ferroan anorthosites. They are present only as possible, perhaps probable, components in some feldspathic granulites (Lindstrom and Lindstrom, 1986). Although anorthosite (presumed to be ferroan) is abundant in much of the lunar highlands (Lucey et al., 1995; Peterson et al., 1996), ferroan anorthosites are absent from the low-K Fra Mauro melt breccias at Apollo 15 and 17 and rare in the vicinity of those landing sites. Their scarcity in the Imbrium-Serenitatis region of the Moon may reflect heterogeneous accumulation processes in the lunar magma ocean, or perhaps a large crustdestroying impact near the end of magma ocean crystallization. Whatever the cause, the low abundance of ferroan anorthosites in the Imbrium and Serenitatis regions of the Moon is a major anomaly of lunar crustal geology. Indeed, the absence of ferroan anorthosite in this region is suggestive that they are not a major component of feldspathic granulites, which are common, and leads to questions about the origin of the feldspathic nature of such rocks.

\section{CONCLUSIONS}

Minor element abundances of mineral fragments provide evidence for a variety of source contributors to the Serenitatis melt breccias that were collected at the Apollo 17 landing site. Mineral fragments were derived predominantly from $\mathrm{Mg}$-suite types of rock, but a significant contribution from rocks unlike those currently recognized as pristine igneous highlands rocks is also required to account for clinopyroxene and olivine compositions. Gabbroic (i.e., those with significant amounts of clinopyroxene) rocks were more abundant in the target stratigraphy than is generally apparent among lithic fragments in the Apollo sample collection. At best, ferroan anorthosites make a minor contribution to even the plagioclase fragment population of the Serenitatis melt breccias, and mare basalts are similarly scarce or absent. Feldspathic granulites probably contribute to at least the plagioclase population, but older impact melts probably do not. Some very magnesian olivines (up to and including $\mathrm{Fo}_{94}$ ) are derived from previously unknown rocks and greatly exacerbate the problem of high-mg* troctolites in the lunar crust. 


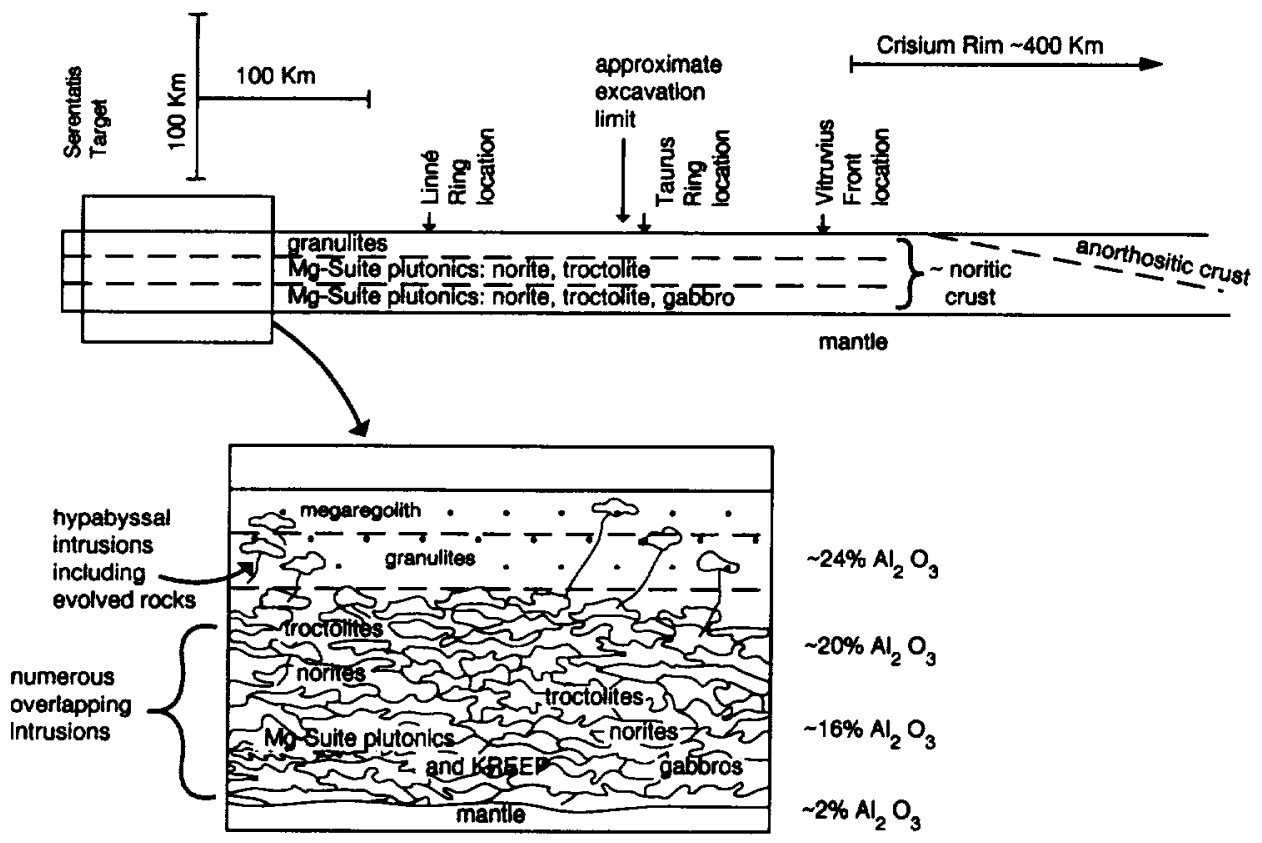

Fig. 15. Inferred West-East schematic cross section for the lunar crust in the Serenitatis-Taurus region. The crust consists of numerous overlapping plutons derived from independent intrusions of $\mathrm{Mg}$-suite magmas at varied times and crystallizing at varied depths (serial magmatism). More granulitic material exists towards the top, and KREEPbearing lithologies may be more common towards or at the base of the crust. Ferroan anorthosites are absent but may become more common a few hundred kilometers to the east.

The mineral fragments cannot be mixed in their observed proportions to produce the whole-rock compositions of the Serenitatis melt breccias, which are representative of low-K Fra Mauro basalt. A preferential contribution from a rock similar to sodic ferrogabbro can at least partly resolve the discrepancy. The chemical and mineral data suggest that in the Serenitatis region, and extending to the Imbrium region, the deepest crust sampled was aluminous basalt in composition and included gabbroic rocks like sodic ferrogabbro and KREEP in some form. These were overlain by $\mathrm{Mg}$-suite troctolites, norites, and lesser gabbroic rocks, and the nearsurface stratigraphy was dominated by feldspathic granulites, which probably dominate the Taurus-Littrow massifs. This regional stratigraphic column contains negligible, if any, ferroan anorthosite. The mineral fragment populations attest to a great variety of source rocks formed at varied depths from different parent magmas. They are not derived from one pluton, or even a small number of plutons, but a large number of both deep and shallow intrusives. Serial magmatism was the dominant mechanism of crustal construction in this particular region of the Moon that includes both the Serenitatis and the Imbrium target areas.

While our study has contributed to the elucidation of the nature of the crust in the Serenitatis-Imbrium region, we are left with at least three tantalizing questions:

1) Why is the diagnostic KREEP and/or sodic ferrogabbro-like component of low-K Fra Mauro basalt melts always cryptic or only represented by a minor amount of fragmental material?

2) Why is ferroan anorthosite, otherwise considered a fundamental component of the earliest lunar crust, absent from this region?
3) What is the feldspathic contributor to feldspathic granulites, which are common in the region, if ferroan anorthosite is not present?

Acknowledgments-Critical reviews by Brad Jolliff, Randy Korotev, and Ross Taylor and comments by the associate editor Chris Koeberl led to improving the presentation of material in this paper. We thank Paul Spudis for discussion of some aspects of this paper. The Lunar and Planetary Institute is operated by the Universities Space Research Association under contract NASW-4066 with the National Aeronautics Administration. This work was supported by the NASA Planetary Materials and Geochemistry Program. Norman was supported by NASA Grant NAGW 3281 in Hawaii, by a National Research Council Senior Fellowship at NASA-JSC, and by an Australian Research Fellowship. Taylor was supported in part by NASA Grant NAGW 3281. Ryder extends thanks to Klaus Keil for support under NASA Grant NAG 9-454 for that part of the work done at the University of Hawaii, and to the Alexander von Humboldt Stiftung and to Dieter Stöffler for support for that part of the work done at the Universität Münster, Germany. We thank Jim McGee for providing us with his data on the compositions of plagioclase in ferroan anorthosites. This paper is School of Ocean and Earth Science and Technology Publication AAA, Hawaii Institute of Geophysics Publication BBB, GEMOC Publication 79, and Lunar and Planetary Institute Contribution $\# 898$.

Editorial handling: C. Koeberl

\section{REFERENCES}

AFGIT (Apollo Field Geology Investigation Team) (1973) Geologic exploration of Taurus-Littrow: Apollo 17 landing site. Science 182, 672-680.

Baker M. B., Alves S., and Stolper E. M. (1996) Petrography and petrology of the Hawaii Scientific Drilling Project lavas: Inferences from olivine phenocryst abundances and compositions. $J$. Geophys. Res. 101, 11715-11727. 
Bence A. E. and Papike J. J. (1972) Pyroxenes as recorders of lunar basalt petrogenesis: Chemical trends due to crystal-liquid interaction. Proc. Lunar Sci. Conf. 3, 431-469.

Bersch M. G. (1990) Minor elements in olivines and pyroxenes in lunar pristine highlands rocks: Implications for the formation of the lunar crust. Ph.D. Dissertation, Univ. New Mexico.

Bersch M. G., Taylor G. J., Keil K., and Norman M. D. (1991) Mineral compositions in pristine lunar highlands rocks and the diversity of highland magmatism. Geophys. Res. Lett. 18, 20852088.

Boyd F. R. and Brown G. M. ( 1969 ) Electron-probe study of pyroxene exsolution. Mineral. Soc. Amer. Spec. Publ. 2, 211-216.

Chao E. C. T., Minkin J. A., Thompson C. L., and Huebner J. S. (1975) The petrogenesis of 77115 and its xenocrysts: Description and preliminary interpretation. Proc. Lunar Sci. Conf. 6, $493-$ 515.

Chao E. C. T., Minkin J. A., and Thompson C. L. (1976) The petrology of 77215 , a noritic impact breccia. Proc. Lunar Sci. Conf. 7 , 2287-2308.

Cintala M. J. and Grieve R. A. F. (1994) The effects of differential scaling of impact melt and crater dimensions on lunar and terrestrial craters: Some brief examples. In Large Meteorite Impacts and Planetary Evolution (ed. B. O. Dressler et al.);Geol. Soc. Amer. Spec. Paper 293, 51-59.

Cushing J. A., Taylor G. J., Norman M. D., and Keil K. (1997) The granulitic impactite suite: impact melts and metamorphic breccias of the early lunar crust. Submitted to Earth Planet Sci. Lett. (submitted).

Dalton J. A. and Lane S. J. (1996) Electron microprobe analysis of $\mathrm{Ca}$ in olivine close to grain boundaries: The problem of secondary $\mathrm{X}$-ray fluorescence. Amer. Mineral. 81, 194-201.

Dalrymple G. B. and Ryder G. (1993) ${ }^{40} \mathrm{Ar} /{ }^{39} \mathrm{Ar}$ age spectra of Apollo 15 impact melt rocks by laser step-heating and their bearing on the history of lunar basin formation. J. Geophys. Res. Planet. 98, 13085-13095.

Dalrymple G. B. and Ryder G. (1996) ${ }^{40} \mathrm{Ar} /{ }^{39} \mathrm{Ar}$ laser step heating ages of some Apollo 17 melt rocks and the age of the Serenitatis impact. Lunar Planet. Sci. XXVII, 285-286.

Dalrymple G. B. and Ryder G. (1996) ${ }^{40} \mathrm{Ar} /{ }^{39} \mathrm{Ar}$ age spectra of Apollo 17 highlands breccia samples by laser step-heating and the age of the Serenitatis basin. J. Geophys. Res. Planet. 101, 22069-22084.

Donaldson C. H. (1975a) A petrogenetic study of harrisite in the Isle of Rhum pluton, Scotland. Ph.D. Thesis Dissertation, St. Andrews Univ.

Donaldson C. H. (1975b) Ultrabasic breccias in layered intrusionsThe Rhum Complex. J. Geol. 83, 33-45.

Dymek R. F., Albee A. L., and Chodos A. A. (1975) Comparative petrology of lunar cumulate rocks of possible primary origin: Dunite 72415 , troctolite 76535 , norite 78235 , and anorthosite 62237. Proc. Lunar Sci. Conf. 6, 301-341.

Dymek R. F., Albee A. L., and Chodos A. A. (1976) Petrology and origin of Boulders \#2 and \#3, Apollo 17 Station 2. Proc. Lunar Sci. Conf. 7, 2335-2378

Esat T. M. and Taylor S. R. (1992) Magnesium isotope fractionation in lunar soils. Geochim. Cosmochim. Acta 56, 1025-1031.

Garcia M. O. (1996) Petrography and olvine and glass chemistry of lavas from the Hawaii Scientific Drilling Project. J. Geophys. Res. 101, $11701-11713$.

Gooley R., Brett R., Warner J., and Smyth J. R. (1974) A lunar rock of deep crustal origin: Sample 76535. Geochim. Cosmochim. Acta 38, 1329-1339.

Grieve R. A. F. (1975) Petrology and chemistry of the impact melt at the Mistastin Lake crater, Labrador. Geol. Soc. Amer. Bull. 86, 1617-1629.

Grieve R. A. F. and Floran R. J. (1978) Manicouagan impact melt, Quebec, 2. Chemical interactions with basement and formational processes. J. Geophys. Res. 83, 2761-2771.

Hansen E. C., Steele I. M., and Smith J. V. (1979) Lunar highland rocks: Element partitioning among minerals 1: Electron microprobe analyses of $\mathrm{Na}, \mathrm{Mg}, \mathrm{K}$, and $\mathrm{Fe}$ in plagioclase; $m g$ partitioning with orthopyroxene. Proc. Lunar Planet. Sci. Conf. 10, $627-638$.

Hashimoto A., Kumazawa M., and Onuma N. (1979) Evaporation metamorphism of primitive dust material in the early solar system. Earth Planet. Sci. Lett. 43, 13-21.

Hauri E.H. and Hart S.R. ( 1994) Constraints on melt migration from mantle plumes: A trace element study of peridotite xenoliths from Savai'i, Western Samoa. J. Geophys. Res. 99, 24301-24321.

Head J. W. (1979) Serenitatis multi-ringed basin: Regional geology and basin ring interpretation. Moon Planet. 21, 439-462.

Heiken G., Vaniman D., and French B. M (1991) Lunar Sourcebook. A User's Guide to the Moon. Cambridge Univ. Press.

Helz R. T. and Appleman D. E. (1973) Mineralogy, petrology, and crystallization history of Apollo 16 rock 68415. Proc. Lunar Sci. Conf. 4, 643-659.

Hervig R. L., Smith J. V., Steele I. M., and Dawson J. B. (1980) Fertile and barren Al-Cr-spinel harzburgites from the upper mantle: Ion and electron probe analyses of trace elements in olivine and orthopyroxene: Relation to lherzolites. Earth Planet. Sci. Lett. 50, $41-58$.

Hess P. (1994) Petrogenesis of lunar troctolites. J. Geophys. Res. 99, $19083-19093$

Hess P. C. and Parmentier E. M. (1995) A model for the thermal and chemical evolution of the Moon's interior: Implications for the onset of mare volcanism. Earth Planet. Sci. Lett. 134, 501514.

Humayun M. and Clayton R. N. ( 1995) Potassium isotope geochemistry: Genetic implications of volatile element depletion. Geochim. Cosmochim. Acta 59, 2131-2148.

Jolliff B. L., Rockow K. M., Korotev R. L., and Haskin L. A. ( 1996) Lithologic distribution and geologic history of the Apollo 17 site: The record in soils and small rock particles from the highland massifs. Meteoritics Planet. Sci. 31, 116-145.

Jones J. H. and Delano J. W. (1989) A three component model for the bulk composition of the Moon. Geochim. Cosmochim. Acta. $53,513-527$.

Jurewicz A. J. G. and Watson E. B. (1988) Cations in olivine, Part 2: Diffusion in olivine xenocrysts, with applications to petrology and mineral physics. Contrib. Mineral. Petrol. 99, 186-201.

Köhler T.P. and Brey G. P. (1990) Calcium exchange between olivine and clinopyroxene calibrated as a geothermobarometer for natural peridotites from 2 to $60 \mathrm{~kb}$ with applications. Geochim. Cosmochim. Acta 54, 2375-2388.

Korotev R. L. ( 1994 ) Compositional variation in Apollo 16 impact melt breccias and inferences for the geology and bombardment history of the Central Highlands of the Moon. Geochim. Cosmochim. Acta 58, 3931-3969.

Korotev R. L. and Kremser D. T. (1992) Compositional variations in Apollo 17 soils and their relationship to the geology of the Taurus-Littrow site. Proc. Lunar Planet. Sci. Conf. 22, 275-301.

Lindstrom M. M. and Salpas P. A. (1983) Geochemical studies of feldspathic fragmental breccias and the nature of North Ray Crater ejecta. Proc. Lunar Planet. Sci. Conf. 13, A671-A683.

Lindstrom M. M. and Lindstrom D. J. (1986) Lunar granulites and their precursor anorthositic norites of the early lunar crust. Proc. Lunar Planet. Sci. Conf. 16, D263-D276.

Longhi J., Walker D., and Hays J. F. (1976) Iron and magnesium in plagioclase. Proc. Lunar Sci. Conf. 7, 1281-1300.

Lucey P.G. and Hawke B.R. (1988) A remote mineralogic perspective on gabbroic units in the lunar highlands. Proc. Lunar Planet. Sci. Conf. 18, 355-363.

Lucey P. G., Taylor G. J., and Malaret E. (1995) Abundance and distribution of Fe on the Moon. Science 268, 1150-1153.

Lucey P. G., Taylor G. J., Hawke B. R., and Spudis P. D. (1996) Iron and titanium concentrations in South Pole-Aitken basin: Implications for lunar mantle composition and basin formation. $\mathrm{Lu}$ nar Planet. Sci. XXVII, 783-784.

Marti K. et al. (1983) Pieces of the ancient lunar crust: Ages and composition of clasts in consortium breccia 67915. Proc. Lunar Planet. Sci. Conf. 14, B165-B175.

McCallum I. S. and O'Brien H. E. ( 1995 ) Lunar crustal stratigraphy inferred from cooling rate studies of exsolved pyroxenes. Lunar Planet Sci. XXVI, 919-920.

McCallum I. S. and O'Brien H. E. (1996) Lunar crustal stratigraphy. Lunar Planet Sci. XXVII, 837-838.

McCormick K. A., Taylor G. J., Keil K., Spudis P. D., Grieve R. A. F., and Ryder G. (1989) Sources of clasts in terrestrial 
impact melts: Clues to the origin of LKFM. Proc. Lunar Planet. Sci. Conf. 19, 691-696.

McGee J. J. (1988) Petrology of brecciated ferroan noritic anorthosite 67215. Proc. Lunar Planet. Sci. Conf. 18, 21-31.

McGee J. J. ( 1993) Lunar ferroan anorthosites: Mineralogy, compositional variations, and petrogenesis. J. Geophys. Res. 98, 9089 9105.

Melosh H. J. (1989) Impact Cratering. Oxford Univ. Press.

Meyer C. (1994) Catalog of Apollo 17 Rocks Vol. 4-North Massif. Lyndon B. Johnson Space Center JSC \#26088, Office of the Curator \#87.

Mueller S., Taylor G. J, and Phillips R. J. ( 1988) Lunar composition: A geophysical and petrological synthesis. J. Geophys. Res. 93, 6338-6352.

Norman M. D., Taylor G. J., Spudis P., and Ryder G. ( 1992) Lithologies contributing to the clast population in Apollo $17 \mathrm{LKFM}$ basaltic impact melts. In Workshop on the Geology of the Apollo 17 Landing Site. LPI Tech. Rept. 92-09, Pt. I (ed. G. Ryder et al.), pp. 42-44.

Norman M. D., Keil K., Griffin W. L., and Ryan C. G. (1995) Frag. ments of ancient lunar crust: Petrology and geochemistry of ferroan noritic anorthosites from the Descartes region of the Moon. Geochim. Cosmochim. Acta 59, 831-847.

O'Brien H. E. and McCallum I. S.(1996) The depth of formation of highly evolved lunar rocks. Lunar Planet Sci. XXVII, 975-976.

O'Keefe J. D. and Ahrens T. J. (1994) Impact-induced melting of planetary surfaces. In Large Meteorite Impacts and Planetary Evolution (ed. B.O. Dressler et al.); Geol. Soc. Amer. Spec. Paper 293, $103-109$.

O'Neill H. St. C. (1991) The origin of the Moon and the early history of the Earth-A chemical model, Part 1, The Moon. Geochim. Cosmochim. Acta 55, 1135-1157.

Papike J. J., Taylor L. A., and Simon S. (1991) Lunar minerals. In Lunar Sourcebook (ed. G. H. Heiken et al.), pp. 121-181. Cambridge Univ. Press.

Peterson C. A., Hawke B. R., Lucey P. G., Taylor G. J., Blewett D. T., and Spudis P. D. (1996) Anorthosite on the lunar nearside and farside. Lunar Planer. Sci. XVII, 1025-1026.

Phinney W. C. (1981) Guidebook for the Boulders at Station 6. Apollo 17. Lyndon B. Johnson Space Center. JSC \#17243. Curatorial Branch Publication \#55.

Reed V.S. and Wolfe E. W. (1975) Origin of the Taurus-Littrow massifs. Proc. Lunar Sci. Conf. 6, 2443-2461.

Reid A. M., Warner J., Ridley W. I., and Brown R. W. (1972) Major element composition of glasses in three Apollo 15 soils. Meteoritics 7, 395-415.

Reid A. M., Duncan A. R., and Richardson S. H. (1977) In search of LKFM. Proc. Lunar Sci. Conf. 8, 2321-2338.

Renner R., Nisbet E. G., Cheadle M. J., Arndt N. T., Bickle M. J., and Cameron W.E. (1994) Komatiite flows from the Reliance Formation, Belingwe Belt, Zimbabwe: I. Petrography and mineralogy. J. Petrol. 35, 361-400.

Rhodes J. M. et al. (1974) The relationships between geology and soil chemistry at the Apollo 17 landing site. Proc. Lunar Sci. Conf. 5, 1097-1117.

Ridley W. I., Hubbard N. J., Rhodes J. M., Weismann H., and Bansal B. (1973) The petrology of lunar breccia 15445 and petrogenetic implications. J. Geol. 81, 621-631.

Rockow K. M and Haskin L. A. (1996) Why are Apollo 17 impact melt breccias assigned a Serenitatis origin: A brief critical review. Lunar Planet. Sci. XXVII, 1089-1090.

Ryder G. (1979) The chemical components of highlands breccias. Proc. Lunar Planet. Sci. Conf. 10, 561-581.

Ryder G. (1981) The Apollo 17 highlands: the South Massif soils. Lunar Planet. Sci. XII, 918-920.

Ryder G. (1983) Nickel in olivines and parent magmas of lunar pristine rocks. In Workshop on Pristine Highlands Rocks and the Early History of the Moon LPI Tech. Rept. 83-02 (ed. J. Longhi and G. Ryder), pp. 66-68

Ryder G. (1984a) Most olivine in the lunar highlands is of shallow origin. Lunar Planet. Sci. XV, 707-708.

Ryder G. (1984b) Minor elements in Marjalahti olivine. Meteoritics $19,79-83$.

Ryder G. (1992a) Chemical variation and zoning of olivine in lunar dunite 72415: Near-surface accumulation. Proc. Lunar Planet. Sci. 22, 373-380.

Ryder G. (1992b) Lunar highlands totality from bits and pieces: A whole-rock-geochemistry-free characterization of an evolved hypabyssal igneous gabbro schlieren from the Apollo 17 landing site. Lunar Planet. Sci. XXIII, 1195-1196.

Ryder G. (1993) Catalog of Apollo 17 Rocks Vol. 1-Stations 2 and 3 (South Massif). Lyndon B. Johnson Space Center. JSC \$26088, Office of the Curator \#87.

Ryder G. and Bower J. F. (1977) Petrology of Apollo 15 black-andwhite rocks 15445 and 15455-fragments of the Imbrium impact melt sheet? Proc. Lunar Sci. Conf. 8, 1895-1923.

Ryder G. and Spudis P. (1987) Chemical composition and origin of Apollo 15 impact melts. Proc. Lunar Planet. Sci. Conf. 17, E432-E446.

Ryder G. and Wood J.A. (1977) Serenitatis and Imbrium impact melts: Implications for large-scale layering in the lunar crust. Proc. Lunar Sci. Conf. 8, 655-668.

Ryder G., Stoeser D. B., Marvin U. B., Bower J. F, and Wood J. A. (1975) Boulder 1, Station 2, Apollo 17: Petrology and petrogenesis. The Moon 14, 327-357.

Sanford R. F. and Huebner J. S. (1980) Model thermal history of 77115 and implications for the origin of fragment-laden basalts. In Proc. Conf. Lunar Highlands Crust (ed. J. J. Papike and R. B. Merrill); Geochim. Cosmochim. Acta 12 (suppl.), 253-269.

Scott D. H. (1974) The geologic significance of some lunar gravity anomalies. Proc. Lunar Sci. Conf. 5, 3025-3036.

Simonds C. H. (1975) Thermal regimes in impact melts and the petrology of the Apollo 17 Station 6 boulder. Proc. Lunar Sci. Conf. 6, 641-672.

Simonds C. H., Floran R. J., McGee P. E., Phinney W. C., and Warner J. L. (1978) Petrogenesis of melt rocks, Manicouagan impact structure, Quebec. J. Geophys. Res. 83, 2773-2788.

Simpkin T. and Smith J. V. (1970) Minor-element distribution in olivine. J. Geol. 78, 304-325.

Smith J. V. (1974) Lunar mineralogy: A heavenly detective story, Presidential address, Part 1. Amer. Mineral. 59, 673-680.

Smith J. V., Hansen E. C., and Steele I. M. (1980) Lunar highlands rocks: Element partitioning among minerals II: electron microprobe analyses of $\mathrm{Al}, \mathrm{P}, \mathrm{Ca}, \mathrm{Ti}, \mathrm{Cr}, \mathrm{Mn}$, and $\mathrm{Fe}$ in olivine. Proc. Lunar Planet. Sci. Conf. 11, 555-569.

Spudis P. D. ( 1984 ) Apollo 16 site geology and impact melts: Implications for the geologic history of the lunar highlands. Proc. Lunar Planet. Sci. Conf. 15, C95-C107.

Spudis P. D. (1993) The Geology of Multi-ring Impact Basins. Cambridge Univ. Press.

Spudis P. D. and Davis P. A. (1986) A chemical and petrologic model of the lunar crust and implications for lunar crustal origin. Proc. Lunar Planet. Sci. Conf. 15, C95-C107.

Spudis P. D. and Ryder G. (1981) Apollo 17 impact melts and their relation to the Serenitatis basin. In Multi-Ring Basins (ed. P. H. Schultz and R. B. Merrill); Proc. Lunar Planet. Sci. Conf. 12A, 133-148.

Spudis P. D., Ryder G., Taylor G. J., McCormick K. A., Keil K., and Grieve R. A. F. (1991) Sources of mineral fragments in impact melts 15445 and 15455: Toward the origin of low-K Fra Mauro basalt. Proc. Lunar Planet. Sci. 21, 151-165.

Spudis P. D., Hawke B. R., Lucey P. G., Taylor G. J., and Stockstill K. R. (1996) Composition of the ejecta deposits of selected lunar basins from Clementine elemental maps. Lunar Planet. Sci. XXVII, $1255-1256$.

Steele I. M. and Smith J. V. ( 1975 ) Minor elements in lunar olivine as a petrologic indicator. Proc. Lunar Sci. Conf. 6, 451-467.

Stockstill K. and Ryder G. (1995) Character and significance of the small variation in chemistry among the Serenitatis impact melt breccias at Taurus-Littrow. Geol. Soc. Amer. Abstr. Progs. 27, A290 (abstr.).

Stöffler D. et al. 1985 ) Composition and evolution of the lunar crust in the Descartes Highlands, Apollo 16. Proc. Lunar Planet. Sci. Conf. 15, C449-C506.

Taylor S. R. (1982) Planetary Science: A Lunar Perspective. Lunar Planet. Inst.

Taylor R. N., Nesbitt R. W., Vidal P., Harmon R. S., Auvray B., and Croudace I. W. (1994) Mineralogy, chemistry, and genesis 
of the boninite series volcanics, Chichijima, Bonin Islands, Japan. J. Petrol. 35, 577-617.

Thornber C. R. and Huebner J. S. (1980) An experimental study of the thermal history of fragment-laden basalt 77115. In Proc. Conf. Lunar Highlands Crust (ed. J. J. Papike and R. B. Merrill); Geochim. Cosmochim. Acta 12 (suppl.), 233-252.

Vaniman D. T. and Papike J. J. (1980) Lunar highland melt rocks: Chemistry, petrology, and silicate mineralogy. In Proc. Conf. Lunar Highlands Crust (ed. J. J. Papike and R. B. Merrill); Geochim. Cosmochim. Acta Suppl. 12 (suppl.), 271-337.

Warner J. L., Simonds C. H., and Phinney W. C. (1976) Apollo 17, Station 6 boulder samples 76255: Absolute petrology of breccia matrix and igneous clasts. Proc. Lunar Sci. Conf. 7, 2233-2250.

Warner J. L., Phinney W. C., Bickel C.E., and Simonds C. H. (1977) Feldspathic granulitic impactites and pre-final bombardment lunar evolution. Proc. Lunar Sci. Conf. 8, 2051-2066.

Warren P. H. (1986) Anorthosite assimilation and the origin of the $\mathrm{Mg} / \mathrm{Fe}$-related bimodality of pristine Moon rocks: Support for the magmasphere hypothesis. Proc. Lunar Planet. Sci. Conf. 16, D331 - D343.

Warren P. H. (1993) A concise compilation of petrologic information on possibly pristine nonmare Moon rocks. Amer. Mineral. 78, 360-376.

Warren P. H. and Wasson J. T. (1978) Compositional-petrographic investigation of pristine non-mare rocks. Proc. Lunar Planet. Sci. Conf. 9, 185-217.

Warren P. H. and Wasson J. T. (1979) The compositional-petrographic search for pristine nonmare rocks: Third foray. Proc. $\mathrm{Lu}$ nar Planet. Sci. Conf. 10, 583-610.
Warren P. H., Jerde E. A., and Kallemeyn G. W. (1991) Pristine Moon rocks: Apollo 17 anorthosites. Proc. Lunar Planet. Sci. 21, $51-61$.

Warren P. H., Claeys P., and Cedillo-Pardo E. (1996) Mega-impact melt petrology (Chicxulub, Sudbury, and the Moon): Effects of scale and other factors on potential for fractional crystallization and development of cumulates. In The Cretaceous-Tertiary Event and other Catastrophes in Earth History (ed. G. Ryder et al.); Geol. Soc. Amer. Spec. Puper 307, 105-124.

Wasson J. T., Warren P. H., Kallemeyn G. W., McEwing C. E., Mittiefehldt D. W., and Boynton W. V. (1977) SCCRV, a major component of highlands rocks. Proc. Lunar Sci. Conf. 8, 22372252.

Wilhelms D. E. (1987) The Geologic History of the Moon. U.S. Geol. Surv. Prof. Paper 1348.

Wilhelms D. E. and McCauley J. F. (1971) Geologic map of the nearside of the Moon. U.S. Geol. Surv., Geol. Atlas of the Moon, Map I-703, scale 1:5,000,000.

Winzer S. R., Nava D. F., Schumann P. J., Lum R. K. L., Lindstrom D. J., and Philpotts J. A. (1977) The Apollo 17 melt sheet: Chemistry, age, and Rb/Sr systematics. Earth Planet. Sci. Lett. 33, 389400.

Wolfe E. W. and Reed V. S. (1976) Geology of the massifs at the Apollo 17 landing site. U.S. Geol. Surv. J. Res. 4, 171-180.

Wolfe E. W. et al. (1981) The Geologic Investigation of the TaurusLittrow Valley: Apollo 17 landing site. U.S. Geol. Surv. Prof. Paper 1008.

Wood J. A. and Hashimoto A. (1993) Mineral equilibrium in fractionated nebular systems. Geochim. Cosmochim. Acta 57, $2377-$ 2388. 
